\title{
Review Article \\ Hierarchical Structures from Inorganic Nanocrystal Self-Assembly for Photoenergy Utilization
}

\author{
Yun-Pei Zhu, ${ }^{1}$ Tie-Zhen Ren, ${ }^{2}$ Tian-Yi Ma, ${ }^{1,3}$ and Zhong-Yong Yuan ${ }^{1}$ \\ ${ }^{1}$ Key Laboratory of Advanced Energy Materials Chemistry (Ministry of Education), \\ Collaborative Innovation Center of Chemical Science and Engineering (Tianjin), College of Chemistry, \\ Nankai University, Tianjin 300071, China \\ ${ }^{2}$ School of Chemical Engineering and Technology, Hebei University of Technology, Tianjin 300130, China \\ ${ }^{3}$ School of Chemical Engineering, University of Adelaide, Adelaide, SA 5005, Australia
}

Correspondence should be addressed to Zhong-Yong Yuan; zyyuan@nankai.edu.cn

Received 7 February 2014; Accepted 7 March 2014; Published 3 April 2014

Academic Editor: Yong Ma

Copyright (C) 2014 Yun-Pei Zhu et al. This is an open access article distributed under the Creative Commons Attribution License, which permits unrestricted use, distribution, and reproduction in any medium, provided the original work is properly cited.

\begin{abstract}
Self-assembly has emerged as a powerful strategy for controlling the structure and physicochemical properties of ensembles of inorganic nanocrystals. Hierarchical structures from nanocrystal assembly show collective properties that differ from individual nanocrystals and bulk samples. Incorporation of structural hierarchy into nanostructures is of great importance as a result of enhancing mass transportation, reducing resistance to diffusion, and high surface areas for adsorption and reaction, and thus much effort has been devoted to the exploration of various novel organizing schemes through which inorganic porous structure with architectural design can be created. In this paper, the recent research progress in this field is reviewed. The general strategies for the synthesis of hierarchical structures assembled from nanobuilding blocks are elaborated. The well-defined hierarchical structures provide new opportunities for optimizing, tuning, and/or enhancing the properties and performance of these materials and have found applications in photoenergy utilization including photodegradation, photocatalytic $\mathrm{H}_{2}$ production, photocatalytic $\mathrm{CO}_{2}$ conversion, and sensitized solar cells, and these are discussed illustratively.
\end{abstract}

\section{Introduction}

With the rapid development of modern society, energy and environmental issues have received tremendous attention. Traditional fossil fuels, such as coal, petroleum, and natural gas, are exceedingly depleted, which is usually accompanied by the emission of harmful chemicals. In response to the energy crisis and environmental contaminations, clean energy and sustainable development are the basic principles. Photoenergy, especially solar energy, is regarded as unlimited and environmental-friendly resource. Notably, where the core ideology lies is the invention and development of advanced functional materials, which is essential for alternative and renewable sources, and reducing the harmful substances [1-3].

Nanomaterials are a kind of advanced materials that exhibit remarkable physicochemical properties. They are promising in various areas, ranging from adsorption, separation, catalysis, sensing, to the burgeoning biotechnology [46]. Just as nanocrystalline particles display properties that are distinct from the bulk samples, the ensembles of nanocrystals should possess collective properties that are different from the individual nanocrystals and bulk materials [7]. Thus recent interest has turned to the ensembles of inorganic nanocrystals and the resultant potential in functional devices $[8,9]$. It is noteworthy that many of these peculiarities and possible applications are mainly dependent on our ability to adjust the self-assembly process and interactions among the electronic, magnetic, and optical properties of the single nanocrystalline building unit. Self-assembly, as a fascinating method for promoting the disordered morphologies of materials into ordered ones, has attracted much interest [10]. Plentiful types of porous materials have been fabricated by self-assembly strategy, such as nanoporous $\mathrm{Mn}_{3} \mathrm{O}_{4}$ [11], 
butterfly-like $\mathrm{CaTiO}_{3}$ dendrite [12], and porous microcapsule [13], which usually involve noncovalent or weak covalent interactions and thus simplify the synthesis technology. Selfassembly has emerged as a powerful, efficient, and facile technique for controlling the porosity and morphologies of the nanocrystalline ensembles $[14,15]$, resulting in extended performances from adsorption/separation to shape-selective catalysis and biology.

Natural materials demonstrate admirable and intriguing hierarchical structures on the basis of comparatively simple components such as brittle minerals with large variety of functions. Nanomaterials with hierarchical architectures at different length scale have been heavily involved in the newly developed photoenergy conversion and storage systems. This is due to that hierarchical porosity and structures present obvious superiorities over other conventional materials in terms of increased mass transport through the pore channels of the materials and maintenance of a specific surface area on the level of fine pore systems, leading to the enhancement of diffusion efficiency and accessibility to the interior interfaces by guest species [16-18]. By incorporation of macroporosity in materials, the improved efficiency of light harvesting can be realized via multiple scattering [19], showing the significance of macrochannels in light relevant systems such as photocatalysis and photovoltaics.

Motivated by the controllable synthesis of nanomaterials, recent efforts have tended to the assembly of nanocrystals into hierarchical architectures. Plentiful 1D, 2D, and 3D secondary assemblies (even super crystals of binary nanocrystal superlattice) have been reported to date [20-24]. Well-ordered assembly composed of tailored nanoscaled building blocks provides new opportunities to enhance the resulting performance. In this review article, we highlight recent advances in self-assembly strategies for constructing hierarchically structured materials. Their involvement in photoenergy utilization including photodegradation, photocatalytic $\mathrm{H}_{2}$ production, photocatalytic $\mathrm{CO}_{2}$ conversion, and sensitized solar cells are elaborated. The intimate linkage between the hierarchically structured materials and the resultant performances in photoenergy storage and conversion can promote the rational design of novel structures with advanced properties.

\section{Strategies for Self-Assembly of Nanocrystals}

2.1. Self-Assembly in the Absence of Templates or External Fields. Self-assembly of nanocrystals without the assistance of templates or external fields is schematically illustrated in Figure 1. Typically, the assembly is governed by the balance of attractive forces (e.g., covalent or hydrogen bonding, electrostatic attraction among the oppositely charged units, depletion forces, or dipole-dipole interactions) and repulsive forces (e.g., steric forces and electrostatic repulsion between ligands of same charge) [25]. Self-organization of nanocrystals generates a variety of structures, including chains $[26,27]$, sheets $[28,29]$, vesicles [30], three-dimensional (3D) crystals [31, 32], and even complicated 3D architectures [33]. The template-free route usually initiates assembly from the weak interaction between the precursor molecules or particles.

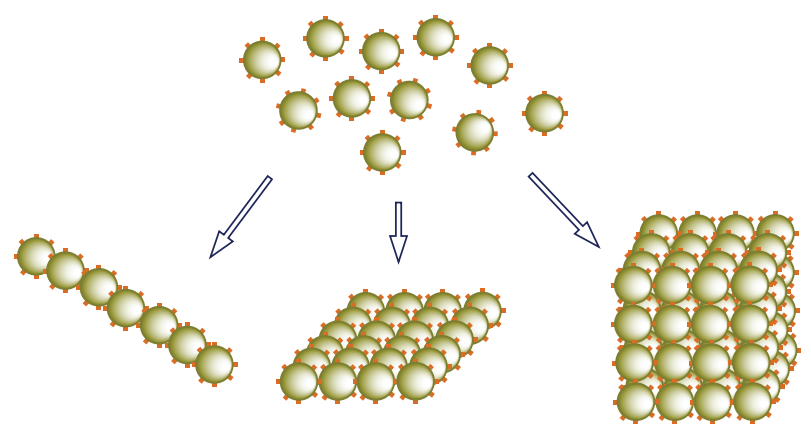

FIGURE 1: Schematic illustration of the organization of nanocrystals into chains, 2D sheets and 3D structures.

Their loosely packing or oriented attachment allows porous morphologies rather than dense materials to be obtained. Various conditions such as precursors, temperature, and solvents can be judiciously adjusted to conduct the selfassembly process. Based on the synthesis systems, different mechanisms and routes have been successfully employed to obtain hierarchical structures.

Oriented aggregation (OA) is a special case of selforganization that provides an important route to produce hierarchical nanostructured materials. This growth mechanism involves the irreversible and crystallographically specific self-assembly of primary nanocrystals [34, 35]. This process is usually driven by the reduction of the surface energy of the whole system [36]. Direct attachment is the most common way. Recent examples include the formation of $1 \mathrm{D}$ nanorods from their respective $0 \mathrm{D}$ nanocrystallites such as $\mathrm{ZnO}$ [37] and $\mathrm{Cu}_{2} \mathrm{O}$ [38]. Site-specific interactions of chemically heterogeneous $\mathrm{Au}$ nanorods would result in end-by-end or side-by-side ensembles, which were driven by triggering attraction between the distinct ligands attached to the long and short facets of the nanorods [39]. Furthermore, two- and three-dimensional OA could be extended to some new architecture. Mesoporous hexagonal nanoplates of manganese oxides were prepared hydrothermally from metal Mn foils/powders and manganese acetate precursors under basic conditions [40]. The oriented aggregation-based assembly of the nanoparticles of mixed $\mathrm{MnOOH} / \mathrm{Mn}_{3} \mathrm{O}_{4}$ phases gave rise to hexagonal nanoplates with irregular mesopores, which transformed into mesoporous single-crystalline $\mathrm{Mn}_{5} \mathrm{O}_{8}$ and $\alpha-\mathrm{Mn}_{2} \mathrm{O}_{3}$ plates after calcination at 400 and $700^{\circ} \mathrm{C}$, respectively. With the increase of calcination temperature, the interior mesopores in each plate were enlarged by the growth and rearrangement of nanocrystals, and the dynamic adjustment of mesopores occurred during the phase transformation and the fusion of nanocrystals, resulting in mesopores regularshaped (polyhedral or even well-defined rectangular). Thus, porous structures could be generated from the noncompact aggregation of these building blocks. That is to say, some surfaces of these building units are not in close contact with others. If the solvent system is properly selected with suitable viscosity and potential barrier, the control of the dynamic process of nanocrystal building blocks in assembly process is feasible. Interestingly, the moving speed, frequency, and 
direction of ligand-free $\mathrm{ZnO}$ nanocrystal building blocks were controllable by designing a methanol/diethyl carbonate/chloroform (MDC) system with suitable viscosity and potential barrier [41]. The synthesized $\mathrm{ZnO}$ nanocrystals could dissolve in methanol and chloroform but not in diethyl carbonate. Thus, the synthesized $\mathrm{ZnO}$ nanocrystals could move freely in methanol/chloroform if diethyl carbonate was not added. However, a potential barrier arised in the solvent system after the addition of diethyl carbonate, which affected evidently the collision process of $\mathrm{ZnO}$ nanocrystals, wherein the coalescence between nanocrystals might take place [42]. Therefore, with aging time extended, the nuclei grew gradually by the $\mathrm{OA}$ of $\mathrm{ZnO}$ nanocrystals both along and perpendicular to the $c$ axis due to the impact of the viscosity and potential barrier [41], leading to the final mesoporous ellipsoids formed with almost perfect crystallographic orientations and high specific surface area of $136 \mathrm{~m}^{2} / \mathrm{g}$.

Nanomaterials with the similar composition but distinct morphologies present substantially different physical, chemical, and mechanical properties. Some typical examples are nanoparticles, nanowires, nanorods, hollow materials, nanotubes, and many other unique structures. Among the various unique structures, hollow nanomaterials have received much research interest due to their special properties including large fractional void space, large specific surface area, low density, and tunable refractive index. $\mathrm{SnO}_{2}$ polyhedra with $3 \mathrm{D}$ hollow structures were synthesized through the OA mechanism [43], while the as-synthesized $\mathrm{SnO}_{2}$ nanocrystallites in a narrow size range of 3-5 $\mathrm{nm}$ could assemble into triangular sheets. With additional two-dimensional crystallite aggregation on the edges, these triangular aggregates could selfturn into three-dimensional hollow octahedra sequentially. The presence of ethylenediamine, in combination with wateralcohol cosolvent, was crucial to the stabilization of $\mathrm{SnO}_{2}$ sheets while maintaining their small crystallite size in this template-free approach.

Besides OA mechanism, the well-known physical phenomenon Ostwald ripening and Kirkendall effect have been widely employed in template-free fabrication of porous nanostructures [44-47]. Based on the combination of Kirkendall effect and Ostwald ripening, mesoporous $\mathrm{SrTiO}_{3}$ nanowires could be synthesized by a template-free hydrothermal process [48]. The Kirkendall effect was the first experimental proof that atomic diffusion occurs through vacancy exchange and not by the direct interchange of atoms. The net directional flow of matter was balanced by an opposite flow of vacancies, which could commonly lead to the formation of porosity [45]. In the hydrothermal system for the synthesis of mesoporous $\mathrm{SrTiO}_{3}$ nanowires, $\mathrm{H}_{2} \mathrm{O}$ and highly concentrated $\mathrm{OH}^{-}$would access the inner fibrous titanate to generate titanium hydroxyl species, which could subsequently react with $\mathrm{Sr}^{2+}$ ions in the outside layer of irregular particles to form $\mathrm{SrTiO}_{3}$. Thus an outward flow of $\mathrm{HTiO}_{3}{ }^{-}$was formed in order to supply enough reagents for the interaction between $\mathrm{HTiO}_{3}{ }^{-}$in the Ti domain and $\mathrm{Sr}^{2+}$ ions in the $\mathrm{Sr}$ domain at the interface of these two moieties; according to the Kirkendall effect, this outward flow of ions should be balanced by the inward flow of vacancies into the fibrous structure.
As the reaction continued, the outside layer of irregular Sr species was continuously consumed in the reaction and incorporated into the fibrous structure, and the surface became smooth and clean, while the mesopores were formed inside the fibers from the condensation of supersaturated vacancies. The $1 \mathrm{D}$ structure grew at the cost of the small particles into longer NWs, with reduction in surface energy as the primary driving force for the morphology evolution. Finally, mesoporous NWs could be obtained (Figure 2), which led to higher photocatalytic activity for the degradation of organic dyes than commercial P25 under UV light excitation. This provides a facile template-free method to prepare cubic perovskite structures of $\mathrm{BaTiO}_{3}$ or even other ternary oxides like $\mathrm{MgTa}_{2} \mathrm{O}_{6}$ and $\mathrm{Co}_{x} \mathrm{Ti}_{1-x} \mathrm{O}_{2-x}$ and some quaternary oxides like $\mathrm{PbZrTiO}_{3}$ and $\mathrm{Ba}_{x} \mathrm{Sr}_{1-x} \mathrm{TiO}_{3}$.

Marvellous interfacial chemistry among various moieties presents a promising platform to synthesize various hierarchical structured materials. Recently, Wang and coworkers have developed a general emulsion-based bottom-up selfassembly (EBS) approach for assembling various kinds of ligand-stabilized nanocrystal building blocks into 3D colloidal spheres with mesoporous characteristics in which an organic ligand played a key role for the successful assembly of 3D microstructures [49-51]. On the other hand, a variety of hierarchical porous nanoarchitectures of different compositions could be prepared through microemulsion methodology. Hierarchical meso-/macroporous hydrangea-like $\mathrm{ZnO}$ $\mathrm{CeO}_{2}$ clusters with an average diameter of $4-5 \mu \mathrm{m}$ were fabricated by the polymerization of mesostructured $\mathrm{ZnO}$ $\mathrm{CeO}_{2}$ sols surrounding the emulsion drops [52]. Squamalike Ce-doped $\mathrm{TiO}_{2}\left(\mathrm{Ce} / \mathrm{TiO}_{2}\right)$ with hierarchical porous structure were also fabricated [14]. The obtained $\mathrm{Ce} / \mathrm{TiO}_{2}$ squamae were hundreds of nanometers in size with an average thickness of $30-50 \mathrm{~nm}$, which aggregated loosely, leaving a disordered arrangement with plenty of interspaces between them and in the inner blocks. Each $\mathrm{Ce} / \mathrm{TiO}_{2}$ sheet was composed of accessible mesopores with a wormhole-like array that were formed by the assembly of the nanoparticles with the regular size of tens of nanometers. A further step could be realized to prepare hierarchical meso-/macroporous phosphonate-based inorganic-organic hybrids $[3,53]$.

It is very attractive and desirable to design a novel approach so that the inorganic nanocrystal units can be used to directly assemble the hierarchical structures under relatively mild conditions. Nevertheless, the control over the dynamic behaviours of inorganic nanocrystals is still difficult due to their tendency to agglomerate. Therefore, a key challenge is how to control the assembling dynamics of nanocrystal building blocks so as to obtain the expected structures instead of a fast and irregular agglomeration.

2.2. Template-Mediated Self-Assembly. A broad range of matrixes can be employed as templates for nanocrystal organization. Strong interactions between nanocrystalline units and templates would favour the arrangement of nanocrystals in structures that are generally predefined by the shapes of the templates. The templates involved in self-assembly can be classified into two categories: hard and soft templates. Hard 


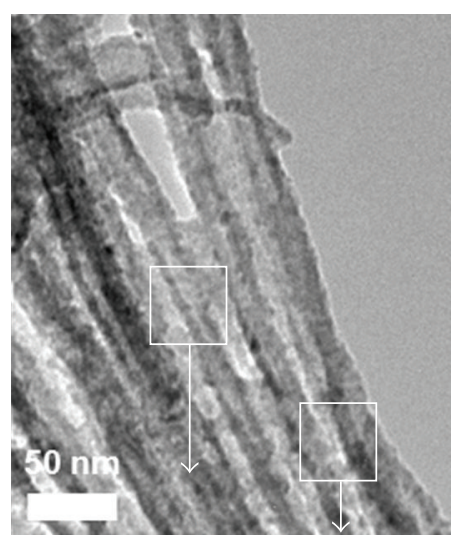

(a)

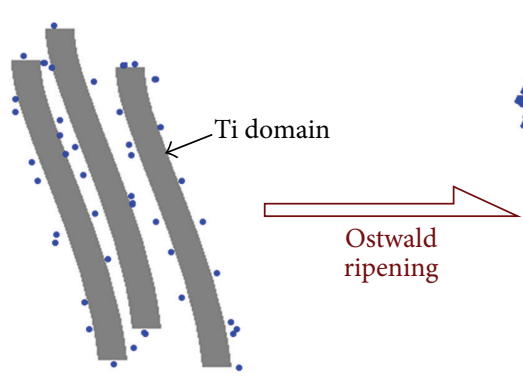

4 hours

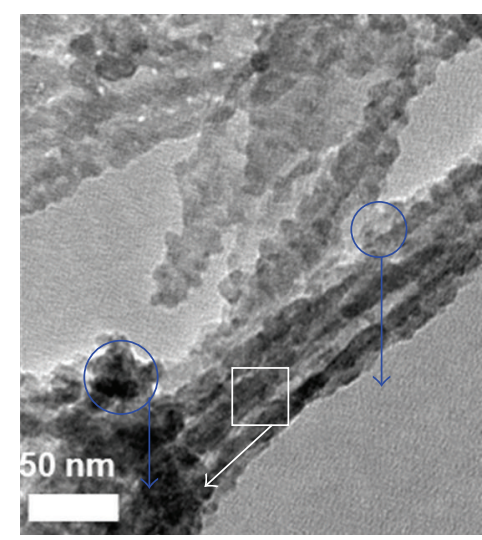

(b)

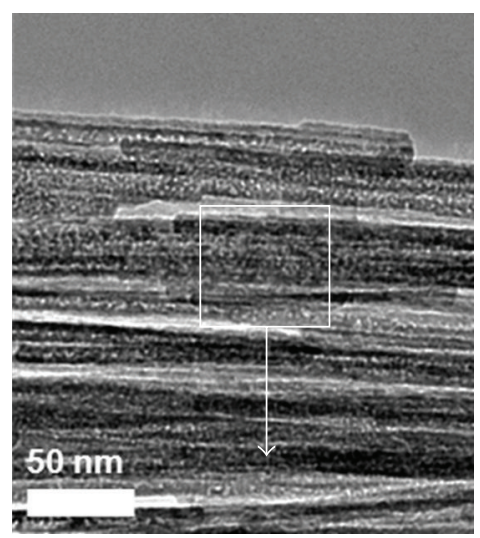

(c)
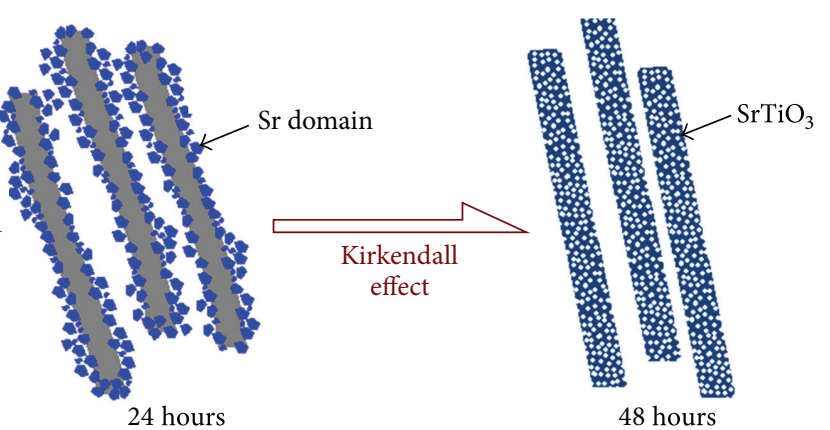

48 hours

(d)

Figure 2: TEM ((a), (b), (c)) images for aliquots of the mixture after autoclaving for different time. A proposed mechanism for the mesoporous NWs (d) [48].

templating method generally involves the accomplishment of preorganized templates, the casting of the precursors, and subsequent removal of templates. With respect to soft templating strategy, the formation of hierarchical structures, based on the specific interaction between supramolecules and nanocrystals, can be realized.

Hard templates such as carbon nanotubes, carbon spheres, silica, and zeolite offer well-defined shapes for nanoparticle assembly [54]. Although the corresponding high efficiency and field, in general, they lack control of the spacing between the deposited nanocrystals. The hierarchical structures in natural materials play a vital role in creating different functionalities and in energy related processes in nature. Biomimic hierarchical porous materials have received great attention $[55,56]$. For example, natural leaves constitute a hierarchical structure that strongly favors efficient light harvesting because of a series of evolutionarily optimized processes including light focusing, multiple scattering and adsorption, propagation, and harvesting. To better understand and use all these efficient natural processes to develop man-made materials "artificial leaves" that may replicate similar processes, natural leaves have been used as biotemplates to replicate all the fine hierarchical structures of leaves using a pure inorganic structure of $\mathrm{TiO}_{2}$ with same hierarchy (Figure 3) [57]. The typical synthesis included the infiltration of inorganic precursors and then the calcination of the biotemplates. All the photosynthetic pigments were replaced by man-made catalysts such as Pt nanoparticles. The obtained leaf replica with catalyst components was used for efficient light-harvesting and photochemical hydrogen production. Compared with $\mathrm{TiO}_{2}$ nanoparticles prepared without biotemplates, the average absorbance intensities within visible range increased $200-234 \%$ for artificial leaves. This should certainly contribute to hierarchical architectures with all the fine structures of leaves imprinted in artificial leaves.

Soft templates possess distinct chemical structures, providing multiple well-defined binding sites for the attachment of nanocrystals. Supramolecular self-assembly provides routes to a range of materials with diverse multicomponent structures of atoms, ions, and/or molecules. The weak noncovalent between supramolecules and nanocrystals can drive inorganic-organic assembly to form inorganic frameworks [58]. Chane-Ching et al. fabricated a series of ordered crystalline nanostructured $\mathrm{CeO}_{2}, \mathrm{ZrO}_{2}$, and $\mathrm{CeO}_{2}-$ $\mathrm{Al}(\mathrm{OH})_{3}$ based upon the cooperative self-assembly of colloidal nanoparticles and a copolymer surfactant [59]. The assembly process was driven by weakly attractive interactions between the surfaces of the nanoparticles and the templates. Also, Yuan et al. reported the spontaneous generation of mesostructured $\mathrm{TiO}_{2}$ having an unusual interior macroporous structure, synthesized in an ethanol solution of surfactant $\mathrm{C}_{16}(\mathrm{EO})_{10}$ containing small quantity of preformed water (Figure 4) [60]. The resulting particles had quite a thick 

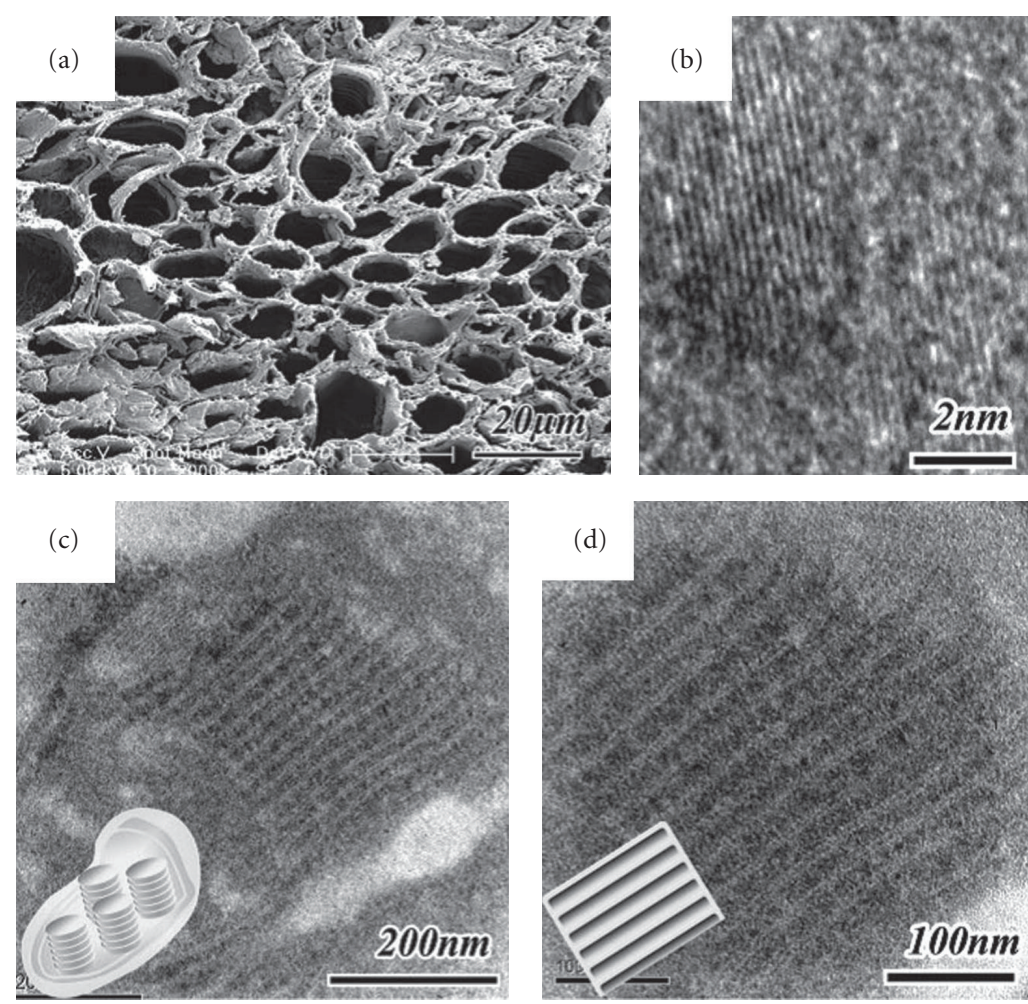

FIGURE 3: (a) SEM image of a cross-section of AIL-TiO ${ }_{2}$ derived from A. vitifolia Buch. leaf. ((b), (c)) TEM images of a layered nanostructure in $\mathrm{AILl}_{-} \mathrm{TiO}_{2}$, with a corresponding illustration of the 3D structures. (d) TEM image of Pt nanoparticles deposited on $\mathrm{TiO}_{2}$ [57].

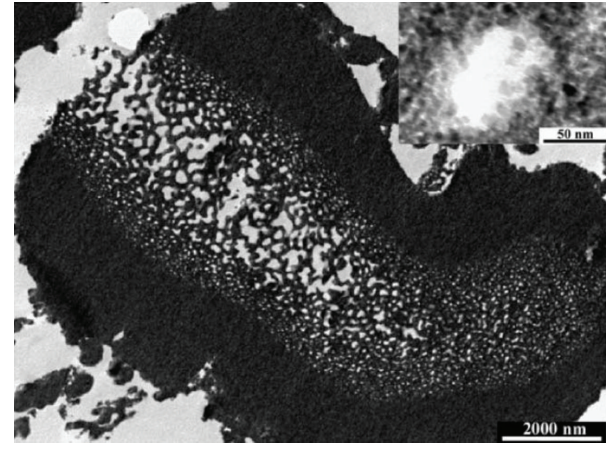

FIGURE 4: Cross-section TEM images of hierarchically mesostructured titania with an interior macroporous structure [60].

shell and a core having a spongelike macroporous structure with a uniform pore size gradient, such that the macropore sizes increased progressively from the shell layer to the core. Both the shell layers and the macroporous framework of the core had a disordered wormhole-like mesoporous structure of $\mathrm{TiO}_{2}$ nanoparticle assembly. It is proposed that this hierarchical structure might be formed by combining a reverse micelle ("quasi-reverse-emulsion") templating pathway with a conventional surfactant templating technique of a hybrid composite mesostructured phase.

Alkoxide hydrolysis has been used extensively to prepare spontaneously the porous metal oxide [61]. A porous network maybe generate by cross-linking of the sol particles thorough an innovative self-formation procedure. Hierarchical meso-/ macroporous metal oxides, such as zirconia [62], alumina [63], and binary mixed oxides [64] have been reported through the surfactant-assisted technique in combination with the hydrolysis from the corresponding single/mixed metal alkoxide precursors. The synthesized materials generally exhibited a parallel-arrayed channel-like macroporous structure, having a dense layer on the face of the monolithic particles under the end of macrochannels. The macroporous framework was composed of accessible mesopores with a wormhole-like array. In fact, various surfactants have been used in the construction of hierarchical porosity, but the surfactants played no role in the formation of micro- and macropores other than to influence the hydrodynamic conditions during synthesis, which could influence the textural properties of the final materials.

Templating methods have proven their generality and high-efficiency in obtaining hierarchically structured materials. Nonetheless, the further removal of the templates may not only perplex the fabrication procedures but also result in the collapse of the frameworks, and even detrimentally introduce some impurities. Thus one should choose a suitable pathway depending on the practical situation.

2.3. Self-Assembly in the Presence of External Fields. Selfassembly of nanocrystals under the action of external fields such as electric or magnetic fields, light, or sonochemistry offers a combination of speed and precision, as well as 
the capability to manipulate nanocrystal assemblies. Magnetic fields have been used for the assembly of metals, metal oxides, and the corresponding nanocomposites. Ferromagnetic nanocrystals with sufficiently pinned magnetic moments undergo spontaneous assembly due to the dipoledipole association, while the application of the magnetic field enhances the organization [65]. Distinctively, superparamagnetic nanocrystals with a randomly changing magnetic moment exerted assembly when torque exerted by a magnetic field exceeds their thermal excitation energy [66]. Electric fields induce polarization of nanoparticles, causing dipole-dipole interactions between adjacent nanoparticles. The strength of interactions increases with increasing polarizability of nanocrystals. It is worthy of noting that ensembles of inorganic nanocrystals usually show up in the form of chains due to the characteristics of the magnetic or electronic field. Moreover, the length of chains changes with the strength of electric field, the concentration of nanoparticles, and the dielectric permittivity of the media $[67,68]$.

Light-assisted self-assembly of nanocrystals depends on optical confinement techniques or irradiation-induced alteration of photoactive ligands $[69,70]$. Especially, azobenzene functional groups undergo trans-cis isomerization under ultraviolet light radiation, and molecules with spirobenzopyran functional groups undergo ring-opening isomerization. When gold nanoparticles stabilized with trans-azobenzene dithiol ligands [70], ultraviolet radiation caused trans-cis isomerization of the ligands and induced molecular dipoles on the azobenzene units, triggering nanoparticle self-assembly into ordered 3D arrays. At high ligand-density, the resultant assemblies were stable without UV irradiation and withstood heating and sonication as well.

The sonochemical method has been extensively employed to generate novel materials with unusual properties and has proven to be efficient for preparing nanomaterials in a short period of time. Physical and chemical effects during the period of ultrasonic irradiation for fragmentation to small particles, acceleration of the reaction, and production of new materials with novel properties are desirable [71]. Hierarchically structured zinc oxides were synthesized at room temperature using ultrarapid sonochemistry and used as photoanodes in dye-sensitized solar cells, showing high photoelectric conversion efficiency of up to $6.42 \%$ under simulated sunlight irradiation [72]. The sonochemical synthesis of nanocrystals embedded in CdS/ZnS/ $\mathrm{In}_{2} \mathrm{~S}_{3}$ complex microspheres has been reported [73]. Mesoporous sphalerite $\mathrm{ZnS}$ nanomaterials with high surface area and well-structured mesoporosity were prepared through a sonochemistry-assisted method in an ethanol system, while the synchronously-formed $\mathrm{NaNO}_{3}$ could inhibit the growth of the $\mathrm{ZnS}$ nanoparticles and further preserve the surface defects (Figure 5) [74]. Ultrasonic waves were essential to obtain a high specific surface area and uniform pore size distribution due to the significant chemical and physical roles of sonochemistry. The synthesized ZnS with valuable optical properties showed outstanding photocatalytic activity for the photodegradation of organic Rhodamine B dye.

A great diversity of external fields, such as magnetic or electronic field, light, and sonochemistry, have been used to obtain sophisticated hierarchical nanostructured materials. The synthesized materials show various architectures and valuable properties. The general syntheses involve special preparation techniques and the physicochemical characteristics of the nanocrystals. Furthermore, the resultant hierarchical structures are adjustable at the microscale, exhibiting great operability and precision.

Template-free routes in the absence of external field to obtain hierarchical nanostructures have initially gained tremendous research interest due to the synthesis simplicity and the resulting wonderful architectures. But the uncontrollability during the synthesis process makes it difficult in preparing the desired structures with high yield and repeatability. Diverse factors have great influence on the structural and porous hierarchy, including the types of precursors, temperature, reaction time, and solvent. By contrast, the templating method has been testified to be an effective way, which is on the basis of replica of the hard templates and the intimate interacting between soft templates and nanocrystals, leading to superior hierarchical structures. Further removal of the templates may perplex the fabrication procedures and result in the collapse of the frameworks and even detrimentally introduce some impurities. This makes it suitable to synthesize materials with solid frameworks such carbons, metal oxides and carbides, and silicas. Much recently, selforganization of nanoparticles assisted by external fields is emerging as a strategy for the preparation of hierarchical, multifunctional structures with programmable properties, which is mainly resulted from the accuracy and homogeneity of external fields over the whole synthesis systems. The direction interaction and even reactions can lead to wellstructured hierarchy. Thus, one should choose the right synthetic strategies to prepare hierarchically structured materials according to the nature of the materials and the ultimate applications.

\section{Applications of Self-Assembled Hierarchical Architectures}

The organization of inorganic nanocrystalline building blocks into hierarchical porous architectures has presented an alternative for preparing interesting architectures of discrete but complex nanocomposites. The rapid growth of emerging applications of these hierarchical architectures in the area of photoenergy utilization including photodegradation, photocatalytic $\mathrm{H}_{2}$ production, photocatalytic $\mathrm{CO}_{2}$ conversion, and sensitized solar cells was also observed. They have displayed much superiority in physicochemical properties and application potential.

3.1. Photodegradation of Contaminants. Construction of ensembles of nanocrystals is desired to combine the initial properties of the nanocrystals with the collective properties. Semiconductor photocatalysts offer huge potential for elimination of toxic chemicals. To improve the photoactivity of the photocatalysts, three key factors should be noted: (1) extension of excitation wavelength; (2) prohibition of charge carrier recombination; and (3) promotion of active 


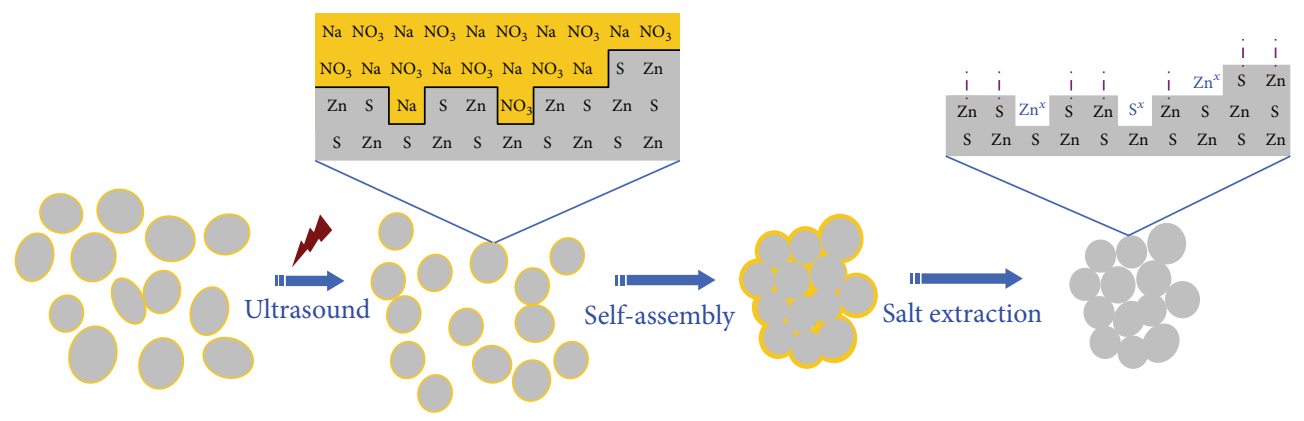

(a)

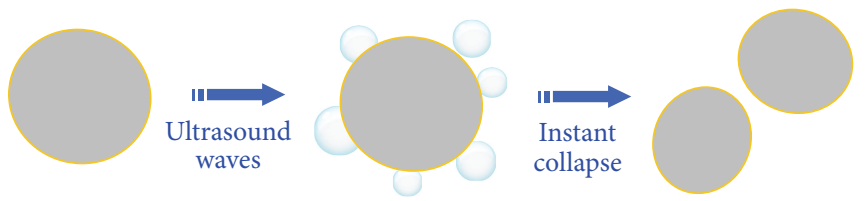

(b)

FIGURE 5: Formation mechanism of mesoporous ZnS nanomaterials (a) and simulated variation to a single nanoparticle during the period of ultrasound irradiation (b) [74].

sites. Attempts have been made and several strategies have been developed as follows [75-79]: (1) doping with foreign elements; (2) surface coupling with other materials so as to build heterostructures; (3) improving the structure of photocatalysts in order to enhance their surface area and porosity. The structural features of these hierarchical structured materials assembled from nanocrystal building blocks promise their uses as potential catalysts in heterogeneous catalysis for bulkier molecules where diffusion of reactant molecules could be facilitated. Hierarchically nanostructured hematite hollow spheres assembled by nanosheets through a microwave-assisted solvothermal route exhibited superior photocatalytic activities in the degradation of salicylic acid [80]. The hollow structure is favorable for the enhancement of the photocatalytic performance. The red-shift of the absorption edge of photocatalysts could even lead to some impressive photocatalytic behaviors under simulated solar light irradiation. Porous $\mathrm{ZnO}$ nanomaterials prepared through assembly of $\mathrm{ZnO}$ nanoclusters in aqueous solution demonstrate good photoactivity in the decomposition of phenol in wastewater [81]. The resulted superior activity than commercial $\mathrm{ZnO}$ powder and $\mathrm{ZnO}$ nanopowder may be attributed to the unique surface features and higher surface area.

Hierarchical structured meso-/macroporous Ce-doped $\mathrm{TiO}_{2}$ [14] and $\mathrm{ZnO}-\mathrm{CeO}_{2}$ binary oxides [52] were found to be effective photocatalysts for photodecomposition of Rhodamine $\mathrm{B}$. The catalysts showed higher photocatalytic reactivity than that of commercial Degussa P25. The hierarchical three-dimensional structure made up of a large number of loosely aggregated porous sheets or clusters could act as a light-transfer path for the distribution of photon energy onto the inner surface of the catalysts, benefiting the photocatalytic ability by increasing the efficiency of photoabsorption and improving mass transfer. Nonmetallic doping such as $\mathrm{F}^{-}$was also testified to be an efficient way to improve the photocatalytic activity of $\mathrm{TiO}_{2}$ microstructures for acetone oxidation [82]. This was due to that fluoride ions not only suppressed the formation of brookite phase but also prevented phase transition of anatase to rutile. Porous titania-phosphonate materials, synthesized through sol-gel method with the use of organically bridged tetra- or penta-phosphonates [83], possess irregular mesoporosity formed by the assembly of nanoparticles in a crystalline anatase phase, while claw molecules of ethylene diamine tetra(methylene phosphonic acid) and diethylene triamine penta(methylene phosphonic acid) were anchored to the titania network homogeneously. These porous titania-phosphonate materials exhibited higher photocatalytic activity in photodecomposition of Rhodamine $\mathrm{B}$ dye molecules than that of mesoporous pure $\mathrm{TiO}_{2}$ whether under UV or visible-light irradiation. This indicated that the homogeneous incorporation of phosphonate groups into the titania framework contributed to the efficient improvement in the photocatalytic ability.

Incorporation of $\mathrm{Ag}$ to the porous "brick-like" $\mathrm{NiFe}_{2} \mathrm{O}_{4}$ superstructure would lead to attractive photovoltage response and remarkable photocatalytic activity in degradation of toluene [84]. The degradation ratio reached to $79.7 \%$ after $6 \mathrm{~h}$ of light irradiation. Alternatively, introduction of carbonaceous nanomaterials with unique structures and properties can add attractive features to photocatalysts. Generally, the photocatalytic enhancement can be assigned to the suppressed recombination of photogenerated charges, extended excitation wavelength, and increased surface-adsorbed reactant, although the underlying mechanisms are still unclear. Graphene has attracted immense attention recently due to the tremendous in-plane conductivity and extraordinary mechanical properties. Du et al. reported the coupling of hierarchically ordered macro-/mesoporous titania films with grapheme by a confined self-assembly method [85]. It was 
found that the existence of interconnected macropores in mesoporous films considerably enhanced the mass transport through the film and increased the accessible surface area within the thin film. The apparent rate constants for macromesoporous films without and with graphene were about 11 and 17 times higher than that of pure mesoporous titania films.

3.2. Photocatalytic $\mathrm{H}_{2}$ Production. Hydrogen has been considered as an alternative energy source and the most potential in the future energy source economy. Dissociation of water to produce hydrogen thus has gathered more attention. However, the unfavorably large energy barrier of this simple progress makes it considerably difficult in the viewpoint of scientific research [86]:

$$
2 \mathrm{H}_{2} \mathrm{O}(\mathrm{l}) \longrightarrow 2 \mathrm{H}_{2}(\mathrm{~g})+\mathrm{O}_{2}(\mathrm{~g}), \quad \Delta G=+474 \mathrm{~kJ} / \mathrm{mol}
$$

The judicious design of a photocatalyst to reduce this activation energy and make the process feasible with photons within the solar spectrum is the core ideology. Since 1972, Fujishima and Honda carried out a pioneering work on photoelectrochemical decomposition of water on electrodes modified by titanium dioxide materials under UV-irradiation [87], a mass of research articles about photocatalysis on water splitting by various pholocatalysts have been largely covered. On the other hand, just a small percentage of the sunlight that reaches the earth's surface is capable of fulfilling the current energy needs of human beings. One of the important tasks is to find advanced materials with suitable structures to use sunlight for photoelectrochemical decomposition of water for $\mathrm{H}_{2}$ production. Accordingly, hierarchal structures from the assembly of nanocrystals endow them with the capability of harvesting light and improving mass transfer owing to the special structural properties.

Leaf skeleton could perform dual roles as a template and a carbon source for the formation of the iron or iron carbide materials through one-step carbothermal reduction of iron (II) precursors [88]. The obtained magnetic iron carbide materials were perfect replicas of a hierarchical leaf skeleton, which could be further used as electrodes for water splitting. This method has great promise for the synthesis of a variety of hierarchically microstructured objects for catalytic and electrochemical purposes due to the biomimic feature. Hierarchical porous structures with enhanced photocatalytic activity for $\mathrm{H}_{2}$ production through facile template-free routes have also been reported recently. Peng and coworkers prepared hierarchical porous $\mathrm{ZnIn}_{2} \mathrm{~S}_{4}$ microspheres using a facile template-free hydrothermal method [89]. The prepared $\mathrm{ZnIn}_{2} \mathrm{~S}_{4}$ demonstrated high photocatalytic $\mathrm{H}_{2}$ production efficiency. The photocatalytic activity could be further enhanced with the assistance of a Pt cocatalyst under visible light irradiation. Moreover, Hartmann et al. compared the photoelectrochemical properties of two kinds of hierarchically porous $\mathrm{TiO}_{2}$ films prepared by the prevalent methods [90]. It was found that sol-gel derived hierarchically porous $\mathrm{TiO}_{2}$ films demonstrated about 10 times higher efficiency for the water splitting reaction than the counterparts prepared from crystalline $\mathrm{TiO}_{2}$ nanoparticles. Indeed, the photocatalytic performance of nanoparticle-based $\mathrm{TiO}_{2}$ films might suffer from insufficient electronic connectivity, while the hierarchical porous $\mathrm{TiO}_{2}$ films through the sol-gel method could provide not only sufficient electronic connectivity but also hierarchically meso-/macroporosity for efficient mass transport and high surface area during the photocatalytic process.

Metal chalcogenide aerogels composed of physically interconnected nanobuilding blocks without organic spacers represent one class of semiconducting inorganic porous nanostructure [91]. Highly porous networks of self-assembled metal chalcogenide gels including aerogels, xerogels, and chalcogels are able to store vast amounts of electric charge, which could be tuned to absorb throughout the solar spectrum for photocatalysis and photovoltaic applications [92]. For example, CuS/ZnS nanoporous nanosheets assembled from nanocrystals exhibited high visible light photocatalytic $\mathrm{H}_{2}$ production activity due to the heterojunctions built between $\mathrm{ZnS}$ and $\mathrm{CuS}$, which could facilitate the interfacial charge transfer [93].

Significant advances have been achieved in the exploring and designing of novel structures for photocatalytic water splitting in the past years. Nevertheless, the efficient and facile synthesis of desired porous materials with well-defined hierarchical structures is still insufficient. Thus further investigation endeavours should be of significance and invested subsequently.

3.3. Hierarchical Structures for $\mathrm{CO}_{2}$ Conversion. The $\mathrm{CO}_{2}$ amount in the earth's atmosphere levels is increasing rapidly with the fast development of industrialization, which has caused the alteration of the temperature of the atmosphere and the acidity of the ocean. Reversely, $\mathrm{CO}_{2}$ can serve as $\mathrm{Cl}$ building block for various organic chemicals. Photocatalytic conversion of thermodynamically stable $\mathrm{CO}_{2}$ into valuable hydrocarbon products has been one feasible option to curtail the rise of the threat [94]. Many kinds of products including formic acid, formaldehyde, methanol, and methane could be obtained during the photocatalytic process, and a multiple reduction process is usually involved:

$$
\begin{gathered}
\mathrm{H}_{2} \mathrm{O}+2 \mathrm{~h}^{+} \longrightarrow \frac{1}{2} \mathrm{O}_{2}+2 \mathrm{H}^{+} \\
\mathrm{CO}_{2} \text { (aq.) }+2 \mathrm{H}^{+}+2 \mathrm{e}^{-} \longrightarrow \mathrm{HCOOH} \\
\mathrm{HCOOH}+2 \mathrm{H}^{+}+2 \mathrm{e}^{-} \longrightarrow \mathrm{HCHO}+\mathrm{H}_{2} \mathrm{O} \\
\mathrm{HCHO}+2 \mathrm{H}^{+}+2 \mathrm{e}^{-} \longrightarrow \mathrm{CH}_{3} \mathrm{OH} \\
\mathrm{CH}_{3} \mathrm{OH}+2 \mathrm{H}^{+}+2 \mathrm{e}^{-} \longrightarrow \mathrm{CH}_{4}+\mathrm{H}_{2} \mathrm{O}
\end{gathered}
$$

where $\mathrm{h}^{+}$and $\mathrm{e}^{-}$represent the photogenerated holes and electrons, respectively. Since hierarchical porous materials possess accessible surface and considerable porosity, the use of porous nanomaterials for photocatalytic $\mathrm{CO}_{2}$ conversion has received much attention recently. For example, it was found that titanium species incorporated mesoporous silicas 
exhibit a much higher activity than bulk $\mathrm{TiO}_{2}$ in the photoreduction of $\mathrm{CO}_{2}$ with water to generate methanol and methane under UV irradiation [95]. After incorporation of $\mathrm{Cu} / \mathrm{TiO}_{2}$ nanocomposites into mesoporous silica through one-pot sol-gel method, the $\mathrm{CO}_{2}$ photoreduction rates were significantly enhanced due to the synergistic combination of $\mathrm{Cu}$ deposition and high surface area silica support [96]. $\mathrm{CO}$ was found to be the primary product of $\mathrm{CO}_{2}$ reduction for $\mathrm{TiO}_{2}-\mathrm{SiO}_{2}$ catalysts without $\mathrm{Cu}$. $\mathrm{CH}_{4}$ was selectively produced when $\mathrm{Cu}$ species was deposited on $\mathrm{TiO}_{2}$. The rate limiting step for this reaction may be the desorption of the reaction intermediates from the active sites.

It is well known that zeolites can offer unique nanoscaled pore reaction fields and an unusual internal surface topology. $\mathrm{TiO}_{2}$ catalysts based on zeolites have been widely studied for photocatalytic reduction of $\mathrm{CO}_{2}$. High efficiency and high selectivity for methanol could be achieved, which might be due to that the charge-transfer excited state of the highly dispersed $\mathrm{TiO}_{2}$ species was thought to play a key role in the high selectivity for $\mathrm{CH}_{3} \mathrm{OH}$, in contrast to the selectivity to $\mathrm{CH}_{4}$ obtained on bulk $\mathrm{TiO}_{2}$ [97]. Ti silicalite molecular sieve (TS1) as photocatalyst under UV light illumination and using methanol as an electron donor could synthesize the main product of formic acid [98]. Up to now, many studies have demonstrated that molecular sieves and porous silica films that coupled with highly dispersed $\mathrm{TiO}_{2}$ active species are promising photocatalysts for photocatalytic $\mathrm{CO}_{2}$ conversion in comparison with bulk $\mathrm{TiO}_{2}$. In addition, a large amount of other semiconductors such as $\mathrm{ZnO}, \mathrm{WO}_{3}, \mathrm{CdS}$, and $\mathrm{ZnS}$ has testified to be effective for photoreduction of $\mathrm{CO}_{2}[99,100]$. Notably, the suitable band-gap positions of semiconductors are indispensable for efficient $\mathrm{CO}_{2}$ photocatalysis conversion.

Considering the hierarchical architectures own special optical properties and porous advantages, the use of hierarchical porous structures for $\mathrm{CO}_{2}$ photoreduction should enhance the efficiency and the selectivity of the products. Disappointedly, there are still rare reports about the practical application of hierarchical structured materials for $\mathrm{CO}_{2}$ photoreduction. Recycling of $\mathrm{CO}_{2}$ via photocatalysis provides a promising approach for $\mathrm{CO}_{2}$ conversion to hydrocarbons which mimics photosynthesis in green plants, showing greater superiorities than the conventional $\mathrm{CO}_{2}$ capture strategy. Correspondingly, the hierarchical architectures replicated from the biotemplates should fit the qualification to be a guide for the rational design of advanced materials for photocatalytic $\mathrm{CO}_{2}$ conversion.

On the other hand, a wide variety of natural plants and some microorganisms can perform $\mathrm{CO}_{2}$ and $\mathrm{H}_{2} \mathrm{O}$ conversion to chemicals by photosynthesis with great efficiency. In order to achieve the benefits of photosynthesis process of $\mathrm{CO}_{2}$ and $\mathrm{H}_{2} \mathrm{O}$ conversion in useful chemical compounds under sunlight irradiation, one can imagine an artificial system performing photosynthesis as leaves and other microorganisms do by encapsulating or immobilizing the biological photosynthetic matter, organelles, and whole cells within an inert support [101]. For instance, the encapsulation of unicellular cyanobacteria and a series of algae have been introduced into 3D hierarchically porous silica matrix for the conversion of water and $\mathrm{CO}_{2}$ under light excitation $[102,103]$.
The immobilized species have shown survival times of up to 5 months with the photosynthetic production of oxygen recorded as much as 17 weeks after immobilization. As a result, the immobilization of cells could allow the continuous exploitation of cells in a nondestructive way to produce metabolites as biofuels. In comparison with well-known photocatalysts (e.g., $\mathrm{TiO}_{2}$ ), which generally reduce $\mathrm{CO}_{2}$ into hydrocarbons under UV irradiation, high temperature, and high pressure [104], these photochemical materials operate under ambient conditions. The environmental impact and energy required are lower. These photochemical materials could thus contribute towards future initiatives in helping to mitigate the energy crisis and reduce $\mathrm{CO}_{2}$ emission.

3.4. Sensitized Solar Cells. As the direct conversion of sunlight to electricity, photovoltaic technology has received much attention. In order to increase solar/electricity efficiency, sensitized solar cells (SSCs) have been intensively investigated since 1991 [105, 106]. Dye-sensitized solar cells (DSSCs) and quantum-dot-sensitized solar cells (QDSSCs) have been widely investigated as next generation solar cells because of their advantages of excellent performance and low production cost [107]. Typical SSCs consisted of three parts: work electrodes (WE), counter electrodes (CE), and liquid or polymeric electrolytes. The WE are crucial in light harvesting, which determines the overall conversion efficiency. The ideal WE should have a well-defined nanostructures to support photoactive dyes and QDs. The presence of hierarchical structures can thus optimize the optical path length and enhance the light absorbance efficiency.

Self-assembly of $\mathrm{TiO}_{2}$ nanoparticles to generate hierarchical pores for DSSCs application has been reported [108, 109]. The resultant high surface area of nanoparticles and hierarchical pores can offer channels for mass transfer and light harvesting. $\mathrm{TiO}_{2}$ spheres with hierarchical pores via grafting polymerization and sol-gel process could be used as photoanodes for DSSCs, showing improved photovoltaic efficiency as compared to the counterpart of smoother $\mathrm{TiO}_{2}$ nanoparticles [108]. This might be due to the increased surface areas and light scattering. $\mathrm{SnO}_{2}$ hollow nanospheres enclosed by single crystalline nanoparticles were prepared by a one-step surfactant-free hydrothermal reaction (Figure 6) [110]. The $\mathrm{SnO}_{2}$ hollow nanospheres could adsorb a large amount of dye molecules due to their large specific surface area and have a high light harvesting efficiency resulting from the light scattering and reflection abilities of their hollow morphology, as well as the efficient charge separation and transport properties of their single crystalline structure, and thus they are a favourable structure for dye-sensitized solar cells. The dye-sensitized solar cells showed a high short-circuit current intensity of $14.59 \mathrm{~mA} / \mathrm{cm}^{2}$ and superior light/electricity conversion efficiency of $6.02 \%$. Particularly, the template-free strategy offers an opportunity to assemble the nanostructures with exposed high surface energy to demonstrate high performance on DSSCs.

$\mathrm{ZnO}$ is a promising candidate for the photoanode of DSSCs. In comparison with $\mathrm{TiO}_{2}, \mathrm{ZnO}$ exhibits similar band gap and the electron-injection process but higher electronic 

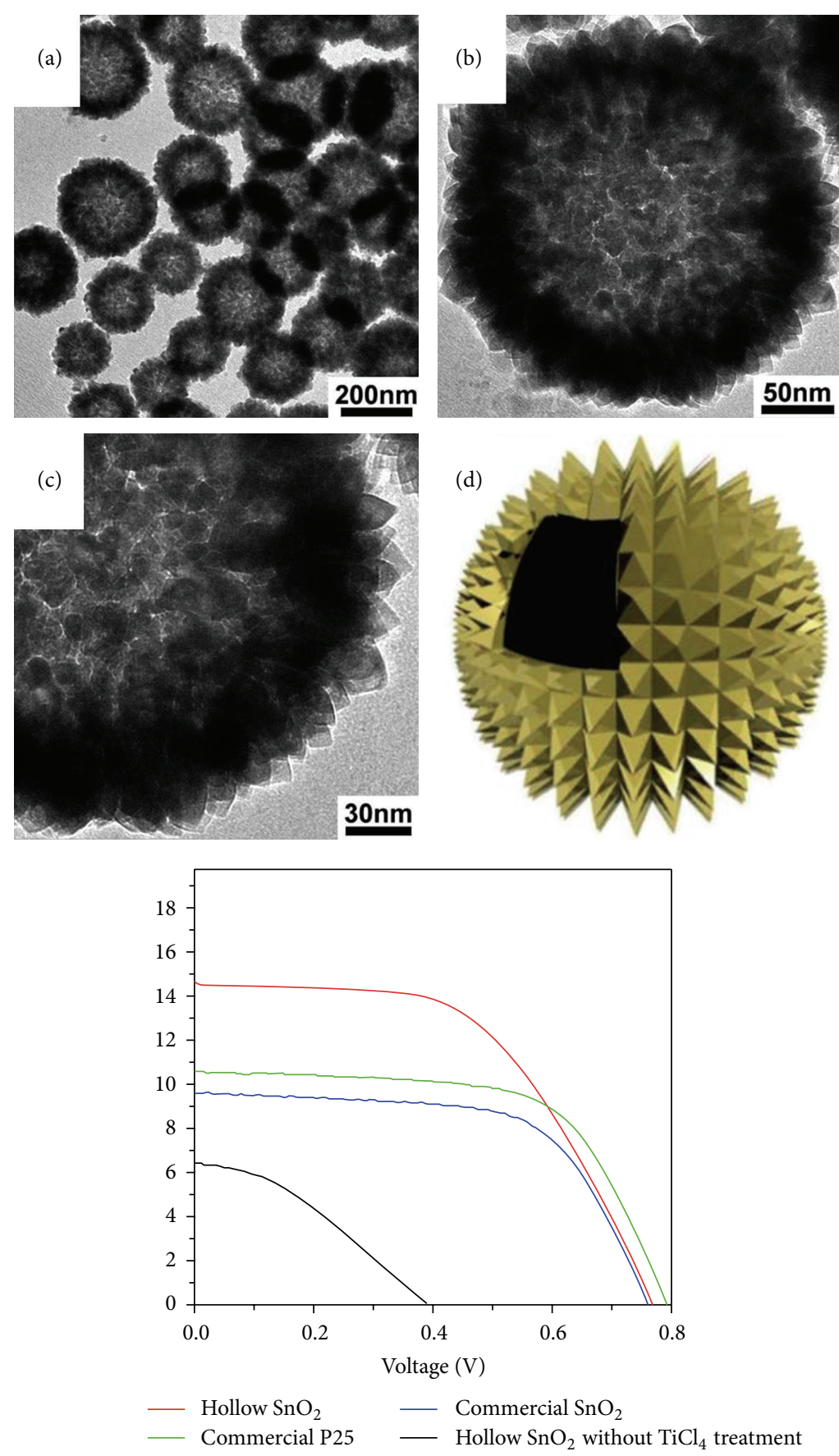

(e)

Figure 6: ((a), (b), (c)) TEM images of $\mathrm{SnO}_{2}$ hollow nanospheres; (d) a schematic image of the hollow sphere; (e) photocurrent-photovoltage

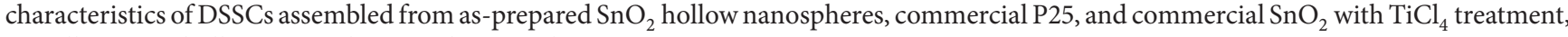
as well as $\mathrm{SnO}_{2}$ hollow nanospheres without $\mathrm{TiCl}_{4}$ treatment [110].

mobility that would favour photoinduced electron transport. The reduced recombination of photoexcited electrons and holes can improve the solar conversion efficiency when used in DSSCs [111]. Chou and coworkers synthesized hierarchically porous $\mathrm{ZnO}$ structures generated through aggregation of $\mathrm{ZnO}$ nanocrystals. A significantly enhanced power conversion efficiency (PCEs) of 5.4\% could be achieved [112-114].
The PCE could further be increased to $6.9 \%$ after modifying the surface of $\mathrm{ZnO}$ with lithium [115]. Cheng and Hsieh fabricated hierarchically structured $\mathrm{ZnO}$ by self-assembly of secondary nanoparticles, which could be used as an effective photoelectrode for DSSCs [116]. The hierarchical architecture could provide more photon harvesting owing to significant light scattering without sacrificing the specific surface area. 
The improvement of the open-circuit photovoltage and the short-circuit photocurrent density of ZnO based DSSCs was ascribed to the effective suppression of electron recombination.

The amount of dye adsorption is one of the key factors to improve solar/electricity conversion efficiency of DSSCs. Besides the conventional DSSCs, an alternative strategy for the construction of new DSSCs was proposed by using hybrid metal sulfonate or phosphonate mesoporous materials with large conjugated hybrid framework [117]. The onepot condensation between metal precursors and dyes allows the molecular-level penetration of large $\pi$-aromatic groups into the semiconductor network homogenously, resulting in an unprecedented large loading amount of organic dyes, but without the disadvantages of dye aggregation and poor electron transmission due to the isolation of single dye centers by surrounding semiconductor oligomers.

In the context of solar energy conversion, QDSSCs are a promising alternative to existing photovoltaic technologies due to the tunable band gap and promise of stable, lowcost performance. Moreover, QDs open up a way to utilize hot electrons and to generate multiple electron-hole pairs with a single photon through impact ionization. Incorporation of QDs into hierarchical porous structures that are assembled from nanocrystal building blocks is provided with the combined photoelectric and structural qualities [118]. CdS quantum dots with surface modified by mercaptosuccinic acid were assembled onto bare $\mathrm{TiO}_{2}$ porous films and presented a better-covered quantum dot monolayer on the $\mathrm{TiO}_{2}$ surface and lower charge transport resistance of the surface linker, both of which were responsible for the conversion efficiencies of QDSSCs [119]. Furthermore, the electron injection yield depends on the distance between QDs and $\mathrm{TiO}_{2}$ and it decreases with the increase of linkage chain length. This is a nonignorable item in understanding functionality of phosphonic linkers and rational design of better photoelectrochemical materials.

\section{Summary and Perspective}

The self-assembly of inorganic nanocrystals into sophisticated hierarchical structures has much promise for advanced materials and devices that may challenge the current lithography techniques and natural architectural designs. A number of assembly processes from nanocrystal building blocks can be harnessed in the creation of hierarchical nanostructured materials. The different interactions between nanocrystallites can force to generate temporary or permanent engagement or interconnection among the nanobuilding blocks. The assembled hierarchical nanostructured materials with improved and tailorable properties have found application potential in the field of photoenergy utilization including photodegradation of contaminants, photocatalytic $\mathrm{H}_{2}$ production, photocatalytic $\mathrm{CO}_{2}$ conversion, and sensitized solar cells. The enhanced performances can be attributed to the high surface area for active sites dispersion and porosity to optimize mass transfer and light harvesting.
However, research in nanomaterials still faces many challenges in synthesis, property characterization, and device fabrication. Synthetic architecture of complex inorganic nanostructures is just in its infancy compared with other wellestablished chemical syntheses. Design rules are urgently needed for the synthesis of hierarchical nanostructured systems by exploiting the analogy of nanoparticles. Robust and highly reproducible synthesis is vital for such studies. Alternatively, rational preparation of inorganic nanocrystals is emerging as a means to enhance their size- and shapedependent properties and thus the self-assembly process. Furthermore, it is of great significance to characterize the process of self-assembly in a much more rigorous manner than is done at present. Simulations of self-assembly with particular thermodynamic parameters and architectural features are emerging as a powerful tool in obtaining novel structures and guiding the formation of existing architectures. To realize the potential of nanocrystalline ensembles, the models and experiments should mutually inform each other. Along the way, principles and methods should be learned that allow us not only to assemble functional nanostructures but also to judiciously design them so that future advances are not exclusively on the basis of experimental trial. And a combination of bottom-up and top-down methods in nanoparticle assembly would lead to large area high-quality hierarchical architectures. The self-organization of nanocrystals with the assistance of surfactant, biotemplates and external fields is emerging as a strategy for the preparation of multifunctional structures with well-structured hierarchy.

\section{Conflict of Interests}

The authors declare that there is no conflict of interests regarding the publication of this paper.

\section{Acknowledgments}

This work was supported by the National Natural Science Foundation of China (20973096, 21073099, and 21076056), the Program for Innovative Research Team in University (IRT13022), and the 111 project (B12015). Zhong-Yong Yuan also thanks the Royal Academy of Engineering for a Research Exchange with China and India Award.

\section{References}

[1] Y. P. Zhu, T. Z. Ren, and Z. Y. Yuan, "Mesoporous non-siliceous inorganic-organic hybrids: a promising platform for designing multifunctional materials," New Journal of Chemistry, 2014.

[2] T. Y. Ma, L. Liu, and Z. Y. Yuan, "Direct synthesis of ordered mesoporous carbons," Chemical Society Reviews, vol. 42, pp. 3977-4003, 2013.

[3] T.-Y. Ma and Z.-Y. Yuan, "Metal phosphonate hybrid mesostructures: environmentally friendly multifunctional materials for clean energy and other applications," ChemSusChem, vol. 4, no. 10, pp. 1407-1419, 2011.

[4] Y. Sun, B. Mayers, and Y. Xia, "Metal nanostructures with hollow interiors," Advanced Materials, vol. 15, no. 7-8, pp. 641646, 2003. 
[5] T. Nakashima and N. Kimizuka, "Interfacial synthesis of hollow $\mathrm{TiO}_{2}$ microspheres in ionic liquids," Journal of the American Chemical Society, vol. 125, no. 21, pp. 6386-6387, 2003.

[6] Y. L. Hou, H. Kondoh, and T. Ohta, "Self-assembly of Co nanoplatelets into spheres: synthesis and characterization," Chemistry of Materials, vol. 17, no. 15, pp. 3994-3996, 2005.

[7] Z. H. Nie, A. Petukhova, and E. Kumacheva, "Properties and emerging applications of self-assembled structures made from inorganic nanoparticles," Nature Nanotechnology, vol. 5, no. 1, pp. 15-25, 2010.

[8] M. R. Buck and R. E. Schaak, "Emerging strategies for the total synthesis of inorganic nanostructures," Angewandte Chemie, vol. 52, pp. 2-27, 2013.

[9] C. M. Doherty, D. Buso, A. J. Hill, S. Furukawa, S. Kitagawa, and P. Falcaro, "Using functional nano- and microparticles for the preparation of metal-organic framework composites with novel properties," Accounts of Chemical Research, vol. 47, pp. 396-405, 2014.

[10] G. M. Whitesides and B. Grzybowski, "Self-assembly at all scales," Science, vol. 295, no. 5564, pp. 2418-2421, 2002.

[11] I. E. Rauda, R. Buonsanti, L. C. Saldarriaga-Lopez et al., "General method for the synthesis of hierarchical nanocrystalbased mesoporous materials," ACS Nano, vol. 6, pp. 6386-6399, 2012.

[12] W. X. Dong, G. L. Zhao, B. Song, G. Xu, J. Zhou, and G. R. Han, "Surfactant-free fabrication of $\mathrm{CaTiO}_{3}$ butterfly-like dendrite via a simple one-step hydrothermal route," CrystEngComm, vol. 14, pp. 6990-6997, 2012.

[13] B. Xie, H. Shi, G. Liu et al., "Preparation of surface porous microcapsules templated by self-assembly of nonionic surfactant micelles," Chemistry of Materials, vol. 20, no. 9, pp. 30993104, 2008.

[14] T.-Y. Ma, J.-L. Cao, G.-S. Shao, X.-J. Zhang, and Z.-Y. Yuan, "Hierarchically structured squama-like cerium-doped titania: synthesis, photoactivity, and catalytic CO oxidation," Journal of Physical Chemistry C, vol. 113, no. 38, pp. 16658-16667, 2009.

[15] Z.-Y. Yuan and B.-L. Su, "Insights into hierarchically mesomacroporous structured materials," Journal of Materials Chemistry, vol. 16, no. 7, pp. 663-677, 2006.

[16] A. Stein, S. G. Rudisill, and N. D. Petkovich, "Perspective on the influence of interactions between hard and soft templates and precursors on morphology of hierarchically structured porous materials," Chemistry of Materials, vol. 26, pp. 259-276, 2014.

[17] T.-Y. Ma, X.-J. Zhang, G.-S. Shao, J.-L. Cao, and Z.-Y. Yuan, "Ordered macroporous titanium phosphonate materials: synthesis, photocatalytic activity, and heavy metal ion adsorption," Journal of Physical Chemistry C, vol. 112, no. 8, pp. 3090-3096, 2008.

[18] T.-Y. Ma, X.-Z. Lin, X.-J. Zhang, and Z.-Y. Yuan, "Hierarchical mesostructured titanium phosphonates with unusual uniform lines of macropores," Nanoscale, vol. 3, no. 4, pp. 1690-1696, 2011.

[19] Y. Li, Z. Y. Fu, and B. L. Su, "Hierarchically structured porous materials for energy conversion and storage," Advanced Functional Materials, vol. 22, pp. 3634-4667, 2012.

[20] T. Q. Wang, X. L. Wang, Y. Lu et al., "Self-assembly of hierarchical $\mathrm{Fe}_{3} \mathrm{O}_{4}$ microsphere/graphene nanosheet composite: towards a promising high-performance anode for Li-ion batteries," $R S C$ Advances, vol. 4, pp. 322-330, 2014.

[21] Y. Zhong, Z. X. Wang, R. F. Zhang et al., "Interfacial self-assembly driven formation of hierarchically structured nanocrystals with photocatalytic activity," ACS Nano, vol. 8, pp. 827-833, 2014.

[22] L.-H. Chen, X.-Y. Li, G. Tian et al., "Highly stable and reusable multimodal zeolite TS-1 based catalysts with hierarchically interconnected three-level micro-meso-macroporous structure," Angewandte Chemie, vol. 50, no. 47, pp. 11156-11161, 2011.

[23] X.-Y. Yang, G. Tian, L.-H. Chen et al., "Well-organized zeolite nanocrystal aggregates with interconnected hierarchically micro-meso-macropore systems showing enhanced catalytic performance," Chemistry, vol. 17, no. 52, pp. 14987-14995, 2011.

[24] R. Dang, L. L. Song, W. J. Dong et al., "Synthesis and selfassembly of large-area $\mathrm{Cu}$ nanosheets and their application as an aqueous conductive ink on flexible electronics," ACS Applied Materials Interfaces, vol. 6, pp. 622-629, 2014.

[25] K. J. M. Bishop, C. E. Wilmer, S. Soh, and B. A. Grzybowski, "Nanoscale forces and their uses in self-assembly," Small, vol. 5, no. 14, pp. 1600-1630, 2009.

[26] Y. J. Kang, K. J. Erickson, and T. A. Taton, "Plasmonic nanoparticle chains via a morphological, sphere-to-string transition," Journal of the American Chemical Society, vol. 127, no. 40, pp. 13800-13801, 2005.

[27] K. K. Caswell, J. N. Wilson, U. H. F. Bunz, and C. J. Murphy, "Preferential end-to-end assembly of gold nanorods by biotinstreptavidin connectors," Journal of the American Chemical Society, vol. 125, no. 46, pp. 13914-13915, 2003.

[28] Z. Y. Tang, Z. L. Zhang, Y. Wang, S. C. Glotzer, and N. A. Kotov, "Self-assembly of CdTe nanocrystals into free-floating sheets," Science, vol. 314, no. 5797, pp. 274-278, 2006.

[29] N. N. Zhao, K. Liu, J. Greener, Z. H. Nie, and E. Kumacheva, "Close-packed superlattices of side-by-side assembled au-cdse nanorods," Nano Letters, vol. 9, no. 8, pp. 3077-3081, 2009.

[30] S. Park, J.-H. Lim, S.-W. Chung, and C. A. Mirkin, "Selfassembly of mesoscopic metal-polymer amphiphiles," Science, vol. 303, no. 5656, pp. 348-351, 2004.

[31] D. Nykypanchuk, M. M. Maye, D. van der Lelie, and O. Gang, "DNA-guided crystallization of colloidal nanoparticles," Nature, vol. 451, no. 7178, pp. 549-552, 2008.

[32] C. R. Iacovella and S. C. Glotzer, "Complex crystal structures formed by the self-assembly of ditethered nanospheres," Nano Letters, vol. 9, no. 3, pp. 1206-1211, 2009.

[33] J. Sharma, R. Chhabra, A. Cheng, J. Brownell, Y. Liu, and H. Yan, "Control of self-assembly of DNA tubules through integration of gold nanoparticles," Science, vol. 323, no. 5910, pp. 112-116, 2009.

[34] J. F. Banfield, S. A. Welch, H. Z. Zhang, T. T. Ebert, and R. L. Penn, "Aggregation-based crystal growth and microstructure development in natural iron oxyhydroxide biomineralization products," Science, vol. 289, no. 5480, pp. 751-754, 2000.

[35] R. L. Penn and J. F. Banfield, "Imperfect oriented attachment: dislocation generation in defect-free nanocrystals," Science, vol. 281, no. 5379, pp. 969-971, 1998.

[36] D. Zitoun, N. Pinna, N. Frolet, and C. Belin, "Single crystal manganese oxide multipods by oriented attachment," Journal of the American Chemical Society, vol. 127, no. 43, pp. 15034-15035, 2005.

[37] J. J. Teo, Y. Chang, and H. C. Zeng, "Fabrications of hollow nanocubes of $\mathrm{Cu}_{2} \mathrm{O}$ and $\mathrm{Cu}$ via reductive self-assembly of $\mathrm{CuO}$ nanocrystals," Langmuir, vol. 22, no. 17, pp. 7369-7377, 2006.

[38] C. Pacholski, A. Kornowski, and H. Weller, "Self-assembly of $\mathrm{ZnO}$ : from nanodots to nanorods," Angewandte Chemie Intenational Edition, vol. 41, no. 7, pp. 1188-1191, 2002. 
[39] Z. H. Nie, D. Fava, E. Kumacheva, S. Zou, G. C. Walker, and M. Rubinstein, "Self-assembly of metal-polymer analogues of amphiphilic triblock copolymers," Nature Materials, vol. 6, no. 8, pp. 609-614, 2007.

[40] T.-Z. Ren, Z.-Y. Yuan, W. Hu, and X. Zou, "Single crystal manganese oxide hexagonal plates with regulated mesoporous structures," Microporous and Mesoporous Materials, vol. 112, no. 1-3, pp. 467-473, 2008.

[41] Y. X. Liu, D. S. Wang, Q. Peng, D. R. Chu, X. W. Liu, and Y. D. Li, "Directly assembling ligand-free $\mathrm{ZnO}$ nanocrystals into threedimensional mesoporous structures by oriented attachment," Inorganic Chemistry, vol. 50, no. 12, pp. 5841-5847, 2011.

[42] X. Xu, F. Liu, K. Yu, W. Huang, B. Peng, and W. Wei, "A kinetic model for nanocrystal morphology evolution," ChemPhysChem, vol. 8, no. 5, pp. 703-711, 2007.

[43] H. G. Yang and H. C. Zeng, "Self-construction of hollow $\mathrm{SnO}_{2}$ octahedra based on two-dimensional aggregation of nanocrystallites," Angewandte Chemie, vol. 43, no. 44, pp. 59305933, 2004.

[44] J. Li and H. C. Zeng, "Hollowing Sn-doped $\mathrm{TiO}_{2}$ nanospheres via Ostwald ripening," Journal of the American Chemical Society, vol. 129, no. 51, pp. 15839-15847, 2007.

[45] A. Cabot, M. Ibáñez, P. Guardia, and A. P. Alivisatos, "Reaction regimes on the synthesis of hollow particles by the Kirkendall effect," Journal of the American Chemical Society, vol. 131, no. 32, pp. 11326-11328, 2009.

[46] H. J. Fan, M. Knez, R. Scholz et al., "Monocrystalline spinel nanotube fabrication based on the Kirkendall effect," Nature Materials, vol. 5, no. 8, pp. 627-631, 2006.

[47] Y. D. Yin, R. M. Rioux, C. K. Erdonmez, S. Hughes, G. A. Somorjal, and A. P. Alivisatos, "Formation of hollow nanocrystals through the nanoscale Kirkendall effect," Science, vol. 304, no. 5671, pp. 711-714, 2004.

[48] T.-Y. Ma, H. Li, T.-Z. Ren, and Z.-Y. Yuan, "Mesoporous $\mathrm{SrTiO}_{3}$ nanowires from a template-free hydrothermal process," RSC Advances, vol. 2, no. 7, pp. 2790-2796, 2012.

[49] F. Bai, D. S. Wang, Z. Y. Huo et al., "A versatile bottomup assembly approach to colloidal spheres from nanocrystals," Angewandte Chemie, vol. 46, no. 35, pp. 6650-6653, 2007.

[50] L. Y. Wang, P. Li, J. Zhuang et al., "Carboxylic acid enriched nanospheres of semiconductor nanorods for cell imaging," Angewandte Chemie, vol. 47, no. 6, pp. 1054-1057, 2008.

[51] C. Chen, C. Y. Nan, D. S. Wang et al., "Mesoporous multicomponent nanocomposite colloidal spheres: ideal high-temperature stable model catalysts," Angewandte Chemie, vol. 50, no. 16, pp. 3725-3729, 2011.

[52] T.-Y. Ma, Z.-Y. Yuan, and Q. J.-L. Cao, "Hydrangea-like mesomacroporous $\mathrm{ZnO}-\mathrm{CeO}_{2}$ binary oxide materials: synthesis, photocatalysis and CO oxidation," European Journal of Inorganic Chemistry, no. 5, pp. 716-724, 2010.

[53] T.-Y. Ma, X.-Z. Lin, X.-J. Zhang, and Z.-Y. Yuan, "High surface area titanium phosphonate materials with hierarchical porosity for multi-phase adsorption," New Journal of Chemistry, vol. 34, no. 6, pp. 1209-1216, 2010.

[54] M. A. Correa-Duarte, J. Pérez-Juste, A. Sánchez-Iglesias, M. Giersig, and L. M. Liz-Marzán, "Aligning Au nanorods by using carbon nanotubes as templates," Angewandte Chemie, vol. 44, no. 28, pp. 4375-4378, 2005.

[55] S. R. Hall, H. Bolger, and S. Mann, "Morphosynthesis of complex inorganic forms using pollen grain templates," Chemical Communications, vol. 9, no. 22, pp. 2784-2785, 2003.
[56] Y. S. Shin, J. Liu, J. H. Chang, Z. M. Nie, and G. Exarhos, "Hierarchically ordered ceramics through surfactant-templated solgel mineralization of biological cellular structures," Advanced Materials, vol. 13, pp. 728-732, 2001.

[57] H. Zhou, X. Li, T. Fan et al., "Artificial inorganic leafs for efficient photochemical hydrogen production inspired by natural photosynthesis," Advanced Materials, vol. 22, no. 9, pp. 951-956, 2010.

[58] H. E. Bakkali, A. Castiñeiras, I. García-Santos, J. M. GonzálezPérez, and J. Niclós-Gutiérrez, "Metallo-supramolecular structures by self-assembly through weak interactions in mixed ligand metal complexes of adenine and malonate," Crystal Growth \& Design, vol. 14, no. 1, pp. 249-260, 2014.

[59] J.-Y. Chane-Ching, F. Cobo, D. Aubert, H. G. Harvey, M. Airiau, and A. Corma, "A general method for the synthesis of nanostructured large-surface-area materials through the selfassembly of functionalized nanoparticles," Chemistry, vol. 11, no. 3, pp. 979-987, 2005.

[60] Z.-Y. Yuan, T.-Z. Ren, and B.-L. Su, "Hierarchically mesostructured titania materials with an unusual interior macroporous structure," Advanced Materials, vol. 15, no. 17, pp. 1462-1465, 2003.

[61] X.-Y. Yang, A. Léonard, A. Lemaire, G. Tian, and B.-L. Su, "Selfformation phenomenon to hierarchically structured porous materials: design, synthesis, formation mechanism and applications," Chemical Communications, vol. 47, no. 10, pp. 2763-2786, 2011.

[62] Z.-Y. Yuan, A. Vantomme, A. Léonard, and B.-L. Su, "Surfactant-assisted synthesis of unprecedented hierarchical meso-macrostructured zirconia," Chemical Communications, vol. 9, no. 13, pp. 1558-1559, 2003.

[63] T.-Z. Ren, Z.-Y. Yuan, and B.-L. Su, "Microwave-assisted preparation of hierarchical mesoporous-macroporous boehmite $\mathrm{AlOOH}$ and gamma- $\mathrm{Al}_{2} \mathrm{O}_{3}$," Langmuir, vol. 20, no. 4, pp. 15311534, 2004.

[64] Z.-Y. Yuan, T.-Z. Ren, A. Vantomme, and B.-L. Su, "Facile and generalized preparation of hierarchically mesoporousmacroporous binary metal oxide materials," Chemistry of Materials, vol. 16, no. 24, pp. 5096-5106, 2004.

[65] S. L. Tripp, R. E. Dunin-Borkowski, and A. Wei, "Flux closure in self-assembled cobalt nanoparticle rings," Angewandte Chemie, vol. 42, no. 45, pp. 5591-5593, 2003.

[66] G. A. Held, G. Grinstein, H. Doyle, S. H. Sun, and C. B. Murray, "Competing interactions in dispersions of superparamagnetic nanoparticles," Physical Review B, vol. 64, Article ID 012408, 124084 pages, 2001.

[67] K. D. Hermanson, S. O. Lumsdon, J. P. Williams, E. W. Kaler, and O. D. Velev, "Dielectrophoretic assembly of electrically functional microwires from nanoparticle suspensions," Science, vol. 294, no. 5544, pp. 1082-1086, 2001.

[68] S. Acharya, I. Patla, J. Kost, S. Efrima, and Y. Golan, "Switchable assembly of ultra narrow CdS nanowires and nanorods," Journal of the American Chemical Society, vol. 128, no. 29, pp. 92949295, 2006.

[69] C. Bechinger, M. Brunner, and P. Leiderer, "Phase behavior of two-dimensional colloidal systems in the presence of periodic light fields," Physical Review Letters, vol. 86, no. 5, pp. 930-933, 2001.

[70] R. Klajn, K. J. M. Bishop, and B. A. Grzybowski, "Lightcontrolled self-assembly of reversible and irreversible nanoparticle suprastructures," Proceedings of the National Academy of 
Sciences of the United States of America, vol. 104, no. 25, pp. 10305-10309, 2007.

[71] G. Cravotto and P. Cintas, "Power ultrasound in organic synthesis: moving cavitational chemistry from academia to innovative and large-scale applications," Chemical Society Reviews, vol. 35, no. 2, pp. 180-196, 2006.

[72] Y. T. Shi, C. Zhu, L. Wang et al., "Ultrarapid sonochemical synthesis of $\mathrm{ZnO}$ hierarchical structures: from fundamental research to high efficiencies up to $6.42 \%$ for quasi-solid dyesensitized solar cells," Chemistry of Materials, vol. 25, pp. 10001012, 2013.

[73] Z. Y. Shen, G. Chen, Q. Wang, Y. G. Yu, C. Zhou, and Y. Wang, "Sonochemistry synthesis and enhanced photocatalytic $\mathrm{H}_{2}$ production activity of nanocrystals embedded in CdS/ZnS/ $/ \mathrm{In}_{2} \mathrm{~S}_{3}$ microspheres," Nanoscale, vol. 4, no. 6, pp. 2010-2017, 2012.

[74] Y. P. Zhu, J. Li, T. Y. Ma, Y. P. Liu, G. H. Du, and Z. Y. Yuan, "Sonochemistry-assisted synthesis and optical properties of mesoporous ZnS nanomaterials," Journal of Materials Chemistry A, vol. 2, pp. 1093-1101, 2014.

[75] X. F. Yang, J. Chen, L. Gong, M. M. Wu, and J. C. Yu, "Crossmedal arrays of Ta-doped rutile titania," Journal of the American Chemical Society, vol. 131, no. 34, pp. 12048-12049, 2009.

[76] S. Shanmugam, A. Gabashvili, D. S. Jacob, J. C. Yu, and A. Gedanken, "Synthesis and characterization of $\mathrm{TiO}_{2} @ \mathrm{C}$ coreshell composite nanoparticles and evaluation of their photocatalytic activities," Chemistry of Materials, vol. 18, no. 9, pp. 22752282, 2006.

[77] H. J. Wang, F. Q. Sun, Y. Zhang et al., "Photochemical growth of nanoporous $\mathrm{SnO}_{2}$ at the air-water interface and its high photocatalytic activity," Journal of Materials Chemistry, vol. 20, no. 27, pp. 5641-5645, 2010.

[78] G.-S. Shao, F.-Y. Wang, T.-Z. Ren, Y. Liu, and Z.-Y. Yuan, "Hierarchical mesoporous phosphorus and nitrogen doped titania materials: synthesis, characterization and visible-light photocatalytic activity," Applied Catalysis B: Environmental, vol. 92, no. 1-2, pp. 61-67, 2009.

[79] G.-S. Shao, X.-J. Zhang, and Z.-Y. Yuan, "Preparation and photocatalytic activity of hierarchically mesoporous-macroporous $\mathrm{TiO}_{2-x} \mathrm{~N}_{x}$," Applied Catalysis B: Environmental, vol. 82, no. 3-4, pp. 208-218, 2008.

[80] S.-W. Cao and Y.-J. Zhu, "Hierarchically nanostructured $\alpha$ $\mathrm{Fe}_{2} \mathrm{O}_{3}$ hollow spheres: preparation, growth mechanism, photocatalytic property, and application in water treatment," Journal of Physical Chemistry C, vol. 112, no. 16, pp. 6253-6257, 2008.

[81] F. Xu, P. Zhang, A. Navrotsky et al., "Hierarchically assembled porous $\mathrm{ZnO}$ nanoparticles: synthesis, surface energy, and photocatalytic activity," Chemistry of Materials, vol. 19, no. 23, pp. 5680-5686, 2007.

[82] J. C. Yu, J. G. Yu, W. K. Ho, Z. T. Jiang, and L. Z. Zhang, "Effects of $\mathrm{F}^{-}$doping on the photocatalytic activity and microstructures of nanocrystalline $\mathrm{TiO}_{2}$ powders," Chemistry of Materials, vol. 14, no. 9, pp. 3808-3816, 2002.

[83] X.-J. Zhang, T.-Y. Ma, and Z.-Y. Yuan, “Titania-phosphonate hybrid porous materials: preparation, photocatalytic activity and heavy metal ion adsorption," Journal of Materials Chemistry, vol. 18, no. 17, pp. 2003-2010, 2008.

[84] Z. R. Zhu, X. Y. Li, Q. D. Zhao, H. Li, Y. Shen, and G. H. Chen, "Porous "brick-like" $\mathrm{NiFe}_{2} \mathrm{O}_{4}$ nanocrystals loaded with Ag species towards effective degradation of toluene," Chemical Engineering Journal, vol. 165, no. 1, pp. 64-70, 2010.

[85] J. Du, X. Lai, N. Yang et al., "Hierarchically ordered macromesoporous $\mathrm{TiO}_{2}$-graphene composite films: improved mass transfer, reduced charge recombination, and their enhanced photocatalytic activities," ACS Nano, vol. 5, no. 1, pp. 590-596, 2011.

[86] M. D. Hernández-Alonso, F. Fresno, S. Suárez, and J. M. Coronado, "Development of alternative photocatalysts to $\mathrm{TiO}_{2}$ : challenges and opportunities," Energy and Environmental Science, vol. 2, no. 12, pp. 1231-1257, 2009.

[87] A. Fujishima and K. Honda, "Electrochemical photolysis of water at a semiconductor electrode," Nature, vol. 238, no. 5358, pp. 37-38, 1972.

[88] Z. Schnepp, W. Yang, M. Antonietti, and C. Giordano, "Biotemplating of metal carbide microstructures: the magnetic leaf," Angewandte Chemie, vol. 49, no. 37, pp. 6564-6566, 2010.

[89] B. Chai, T. Peng, P. Zeng, X. Zhang, and X. Liu, "Templatefree hydrothermal synthesis of $\mathrm{ZnIn}_{2} \mathrm{~S}_{4}$ floriated microsphere as an efficient photocatalyst for $\mathrm{H}_{2}$ production under visiblelight irradiation," Journal of Physical Chemistry C, vol. 115, no. 13, pp. 6149-6155, 2011.

[90] P. Hartmann, D.-K. Lee, B. M. Smarsly, and J. Janek, "Mesoporous $\mathrm{TiO}_{2}$ : comparison of classical sol-gel and nanoparticle based photoelectrodes for the water splitting reaction," ACS Nano, vol. 4, no. 6, pp. 3147-3154, 2010.

[91] S. Bag, I. U. Arachchige, and M. G. Kanatzidis, "Aerogels from metal chalcogenides and their emerging unique properties," Journal of Materials Chemistry, vol. 18, no. 31, pp. 3628-3632, 2008.

[92] I. U. Arachchige and S. L. Brock, "Sol-gel assembly of CdSe nanoparticles to form porous aerogel networks," Journal of the American Chemical Society, vol. 128, no. 24, pp. 7964-7971, 2006.

[93] J. Zhang, J. G. Yu, Y. M. Zhang, Q. Li, and J. R. Gong, "Visible light photocatalytic $\mathrm{H}_{2}$-production activity of $\mathrm{CuS} / \mathrm{ZnS}$ porous nanosheets based on photoinduced interfacial charge transfer," Nano Letters, vol. 11, no. 11, pp. 4774-4779, 2011.

[94] H.-C. Yang, H.-Y. Lin, Y.-S. Chien, J. C.-S. Wu, and H.-H. $\mathrm{Wu}$, "Mesoporous $\mathrm{TiO}_{2} / \mathrm{SBA}-15$, and $\mathrm{Cu} / \mathrm{TiO}_{2} / \mathrm{SBA}-15$ composite photocatalysts for photoreduction of $\mathrm{CO}_{2}$ to methanol," Catalysis Letters, vol. 131, no. 3-4, pp. 381-387, 2009.

[95] J.-S. Hwang, J.-S. Chang, S.-E. Park, K. Ikeue, and M. Anpo, "Photoreduction of carbondioxide on surface functionalized nanoporous catalysts," Topics in Catalysis, vol. 35, no. 3-4, pp. 311-319, 2005.

[96] Y. Li, W.-N. Wang, Z. Zhan, M.-H. Woo, C.-Y. Wu, and P. Biswas, "Photocatalytic reduction of $\mathrm{CO}_{2}$ with $\mathrm{H}_{2} \mathrm{O}$ on mesoporous silica supported $\mathrm{Cu} / \mathrm{TiO}_{2}$ catalysts," Applied Catalysis B: Environmental, vol. 100, no. 1-2, pp. 386-392, 2010.

[97] G. N. Nomikos, P. Panagiotopoulou, D. I. Kondarides, and X. E. Verykios, "Kinetic and mechanistic study of the photocatalytic reforming of methanol over $\mathrm{Pt} / \mathrm{TiO}_{2}$ catalyst," Applied Catalysis B: Environmental, vol. 146, pp. 249-257, 2014.

[98] N. Ulagappan and H. Frei, "Mechanistic study of $\mathrm{CO}_{2}$ photoreduction in Ti silicalite molecular sieve by FT-IR spectroscopy," Journal of Physical Chemistry A, vol. 104, no. 33, pp. 7834-7839, 2000.

[99] S. C. Roy, O. K. Varghese, M. Paulose, and C. A. Grimes, "Toward solar fuels: photocatalytic conversion of carbon dioxide to hydrocarbons," ACS Nano, vol. 4, no. 3, pp. 1259-1278, 2010.

[100] H. Takeda and O. Ishitani, "Development of efficient photocatalytic systems for $\mathrm{CO}_{2}$ reduction using mononuclear and multinuclear metal complexes based on mechanistic studies," 
Coordination Chemistry Reviews, vol. 254, no. 3-4, pp. 346-354, 2010.

[101] C. F. Meunier, J. C. Rooke, A. Léonard, H. Xie, and B.-L. Su, "Living hybrid materials capable of energy conversion and $\mathrm{CO}_{2}$ assimilation," Chemical Communications, vol. 46, no. 22, pp. 3843-3859, 2010.

[102] A. Léonard, J. C. Rooke, C. F. Meunier, H. Sarmento, J.-P. Descy, and B.-L. Su, "Cyanobacteria immobilised in porous silica gels: exploring biocompatible synthesis routes for the development of photobioreactors," Energy and Environmental Science, vol. 3, no. 3, pp. 370-377, 2010.

[103] A. Léonard, P. Dandoy, E. Danloy et al., "Whole-cell based hybrid materials for green energy production, environmental remediation and smart cell-therapy," Chemical Society Reviews, vol. 40, no. 2, pp. 860-885, 2011.

[104] S. S. Tan, L. Zou, and E. Hu, "Photocatalytic reduction of carbon dioxide into gaseous hydrocarbon using $\mathrm{TiO}_{2}$ pellets," Catalysis Today, vol. 115, no. 1-4, pp. 269-273, 2006.

[105] B. O’Regan and M. Grätzel, "A low-cost, high-efficiency solar cell based on dye-sensitized colloidal $\mathrm{TiO}_{2}$ film," Nature, vol. 353, pp. 737-739, 1991.

[106] J. Burschka, N. Pellet, S. J. Moon et al., "Sequential deposition as a route to high-performance perovskite-sensitized solar cells," Nature, vol. 499, pp. 316-320, 2013.

[107] S. Rühle, M. Shalom, and A. Zaban, "Quantum-dot-sensitized solar cells," ChemPhysChem, vol. 11, no. 11, pp. 2290-2304, 2010.

[108] J. T. Park, D. Y. Roh, R. Patel, E. Kim, D. Y. Ryu, and J. H. Kim, "Preparation of $\mathrm{TiO}_{2}$ spheres with hierarchical pores via grafting polymerization and sol-gel process for dye-sensitized solar cells," Journal of Materials Chemistry, vol. 20, no. 39, pp. 8521-8530, 2010.

[109] D. Hwang, H. Lee, S.-Y. Jang et al., "Electrospray preparation of hierarchically-structured mesoporous $\mathrm{TiO}_{2}$ spheres for use in highly efficient dye-sensitized solar cells," ACS Applied Materials and Interfaces, vol. 3, no. 7, pp. 2719-2725, 2011.

[110] H. Wang, B. Li, J. Gao et al., " $\mathrm{SnO}_{2}$ hollow nanospheres enclosed by single crystalline nanoparticles for highly efficient dyesensitized solar cells," CrystEngComm, vol. 14, pp. 5177-5181, 2012.

[111] Q. Zhang, C. S. Dandeneau, X. Zhou, and C. Cao, "ZnO nanostructures for dye-sensitized solar cells," Advanced Materials, vol. 21, no. 41, pp. 4087-4108, 2009.

[112] T. P. Chou, Q. F. Zhang, G. E. Fryxell, and G. Z. Cao, "Hierarchically structured $\mathrm{ZnO}$ film for dye-sensitized solar cells with enhanced energy conversion efficiency," Advanced Materials, vol. 19, no. 18, pp. 2588-2592, 2007.

[113] Q. F. Zhang, T. P. Chou, B. Russo, S. A. Jenekhe, and G. Cao, "Aggregation of $\mathrm{ZnO}$ nanocrystallites for high conversion efficiency in dye-sensitized solar cells," Angewandte Chemie, vol. 47, no. 13, pp. 2402-2406, 2008.

[114] Q. F. Zhang, T. P. Chou, B. Russo, S. A. Jenekhe, and G. Z. Cao, "Polydisperse aggregates of $\mathrm{ZnO}$ nanocrystallites: a method for energy-conversion-efficiency enhancement in dyesensitized solar cells," Advanced Functional Materials, vol. 18, no. 11, pp. 1654-1660, 2008.

[115] Q. F. Zhang, C. S. Dandeneau, S. Candelaria et al., "Effects of lithium ions on dye-sensitized $\mathrm{ZnO}$ aggregate solar cells," Chemistry of Materials, vol. 22, no. 8, pp. 2427-2433, 2010.

[116] H.-M. Cheng and W.-F. Hsieh, "High-efficiency metal-free organic-dye-sensitized solar cells with hierarchical $\mathrm{ZnO}$ photoelectrode," Energy and Environmental Science, vol. 3, no. 4, pp. 442-447, 2010.
[117] T.-Y. Ma, Y.-S. Wei, T.-Z. Ren, L. Liu, Q. Guo, and Z.-Y. Yuan, "Hexagonal mesoporous titanium tetrasulfonates with large conjugated hybrid framework for photoelectric conversion," ACS Applied Materials and Interfaces, vol. 2, no. 12, pp. 35633571, 2010.

[118] H. N. Kim, T. W. Kim, I. Y. Kim, and S.-J. Hwang, "Cocatalystfree photocatalysts for efficient visible-light-induced $\mathrm{H} 2$ production: porous assemblies of CdS quantum dots and layered titanate nanosheets," Advanced Functional Materials, vol. 21, no. 16, pp. 3111-3118, 2011.

[119] Y.-J. Shen and Y.-L. Lee, "Assembly of CdS quantum dots onto mesoscopic $\mathrm{TiO}_{2}$ films for quantum dot-sensitized solar cell applications," Nanotechnology, vol. 19, no. 4, Article ID 045602, 2008. 

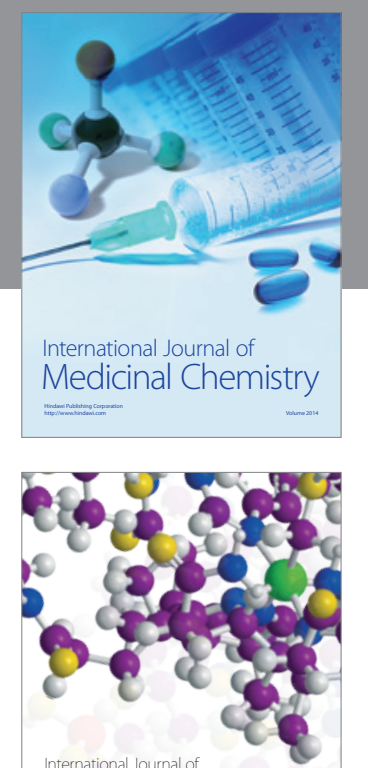

\section{Carbohydrate} Chemistry

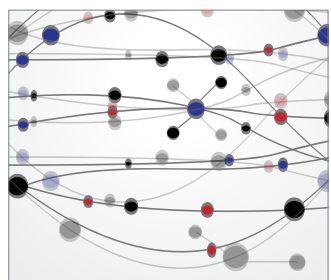

The Scientific World Journal
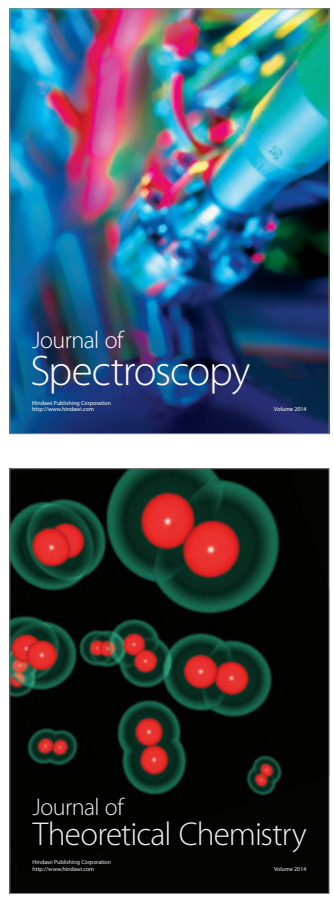
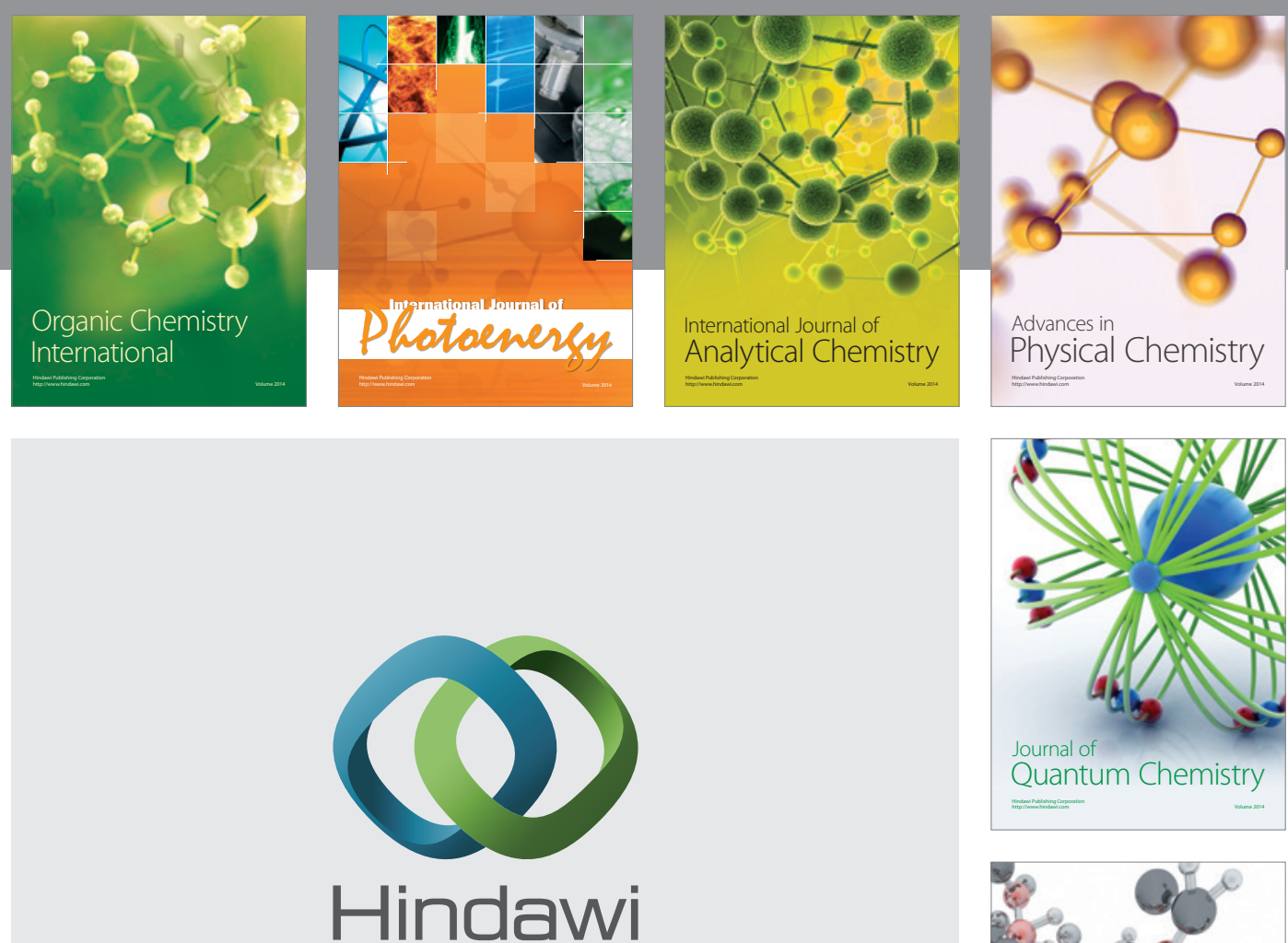

Submit your manuscripts at

http://www.hindawi.com

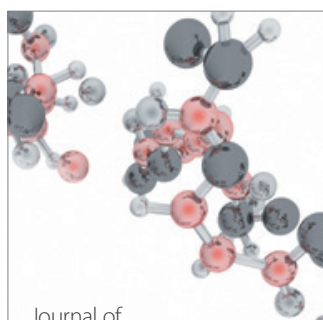

Analytical Methods

in Chemistry

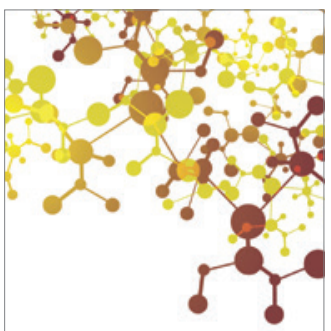

Journal of

Applied Chemistry

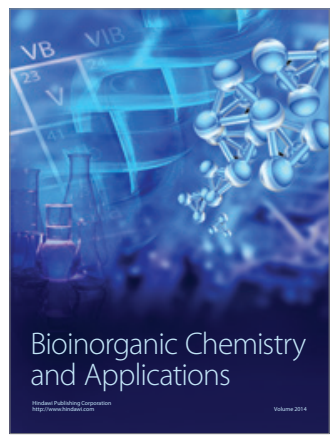

Inorganic Chemistry
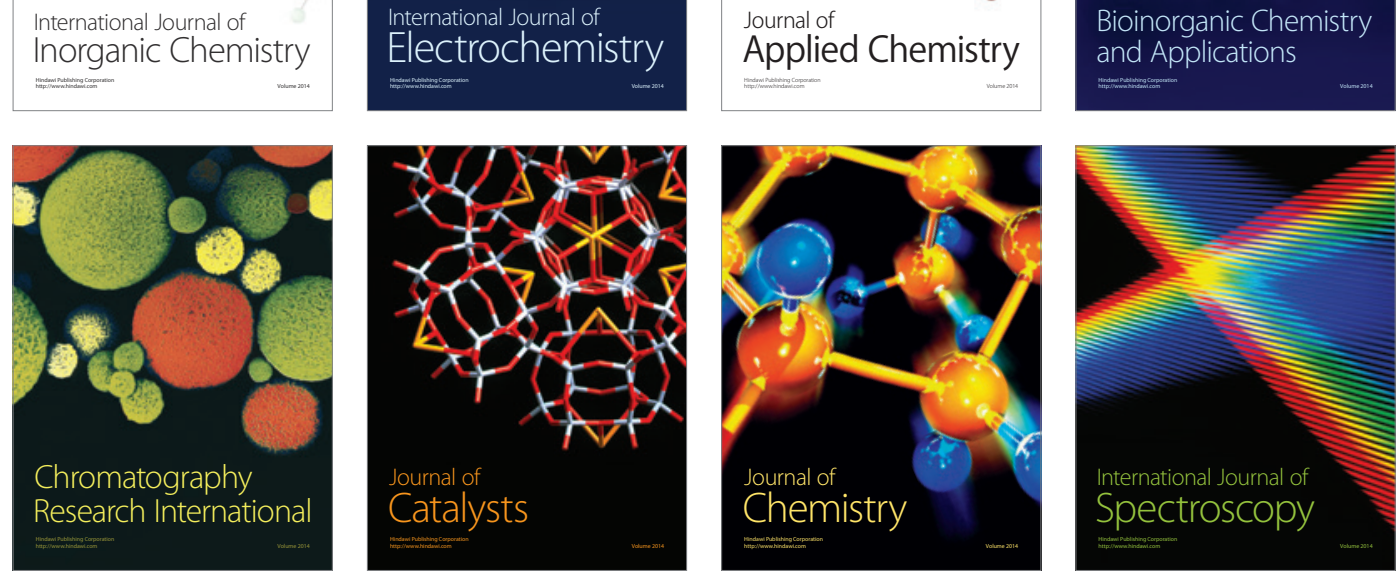